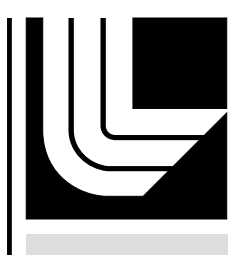

LAW RENCE LIVERMORE N A T IO N A L LABORATORY

Performance Analysis: ITS Data through September 30, 2009

C. E. Kerr

December 10, 2009 
This document was prepared as an account of work sponsored by an agency of the United States government. Neither the United States government nor Lawrence Livermore National Security, LLC, nor any of their employees makes any warranty, expressed or implied, or assumes any legal liability or responsibility for the accuracy, completeness, or usefulness of any information, apparatus, product, or process disclosed, or represents that its use would not infringe privately owned rights. Reference herein to any specific commercial product, process, or service by trade name, trademark, manufacturer, or otherwise does not necessarily constitute or imply its endorsement, recommendation, or favoring by the United States government or Lawrence Livermore National Security, LLC. The views and opinions of authors expressed herein do not necessarily state or reflect those of the United States government or Lawrence Livermore National Security, LLC, and shall not be used for advertising or product endorsement purposes.

This work performed under the auspices of the U.S. Department of Energy by Lawrence Livermore National Laboratory under Contract DE-AC52-07NA27344. 


\section{Performance Analysis: \\ ITS Data through September 30, 2009}

November 16, 2009

Contractor Assurance Office

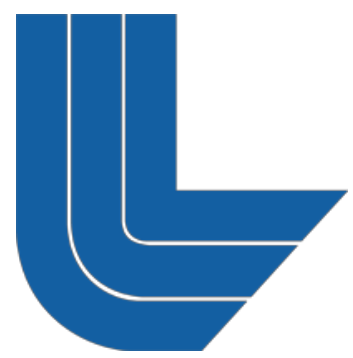




\section{Disclaimer}

This document was prepared as an account of work sponsored by an agency of the United States government. Neither the United States government nor Lawrence Livermore National Security, LLC, nor any of their employees makes any warranty, expressed or implied, or assumes any legal liability or responsibility for the accuracy, completeness, or usefulness of any information, apparatus, product, or process disclosed, or represents that its use would not infringe privately owned rights. Reference herein to any specific commercial product, process, or service by trade name, trademark, manufacturer, or otherwise does not necessarily constitute or imply its endorsement, recommendation, or favoring by the United States government or Lawrence Livermore National Security, LLC. The views and opinions of authors expressed herein do not necessarily state or reflect those of the United States government or Lawrence Livermore National Security, LLC, and shall not be used for advertising or product endorsement purposes.

This work performed under the auspices of the U.S. Department of Energy by Lawrence Livermore National Laboratory under Contract DE-AC52-07NA27344. 


\section{Contents}

1.0 SUMMARY

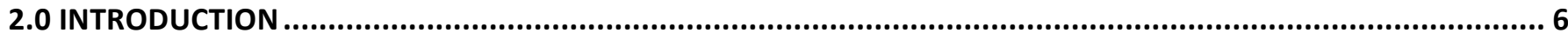

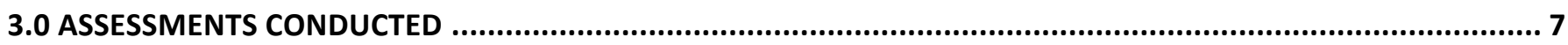

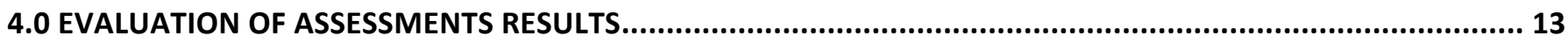

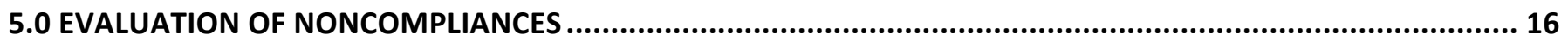

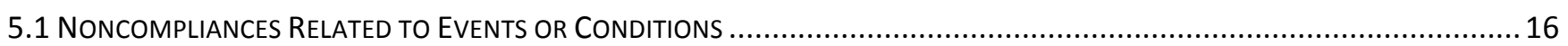

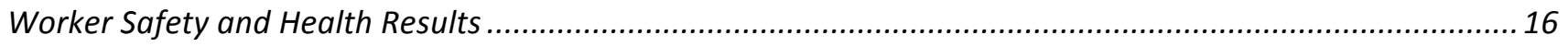

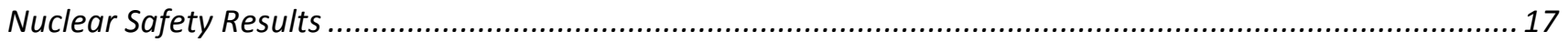

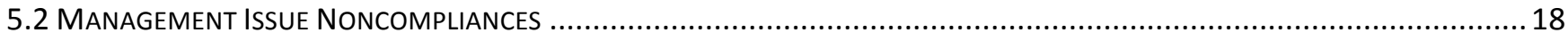

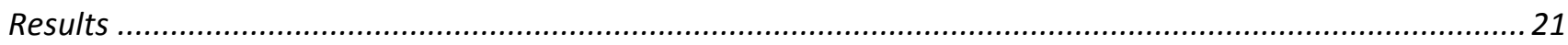

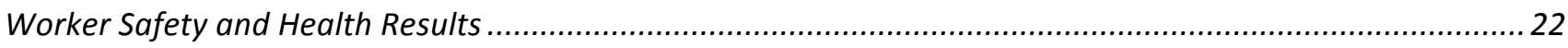

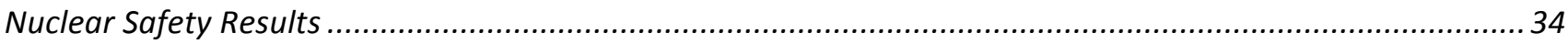

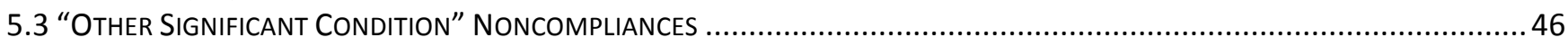

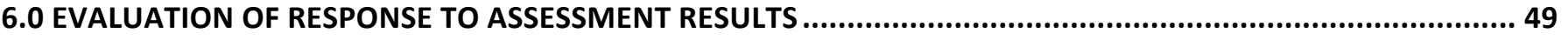

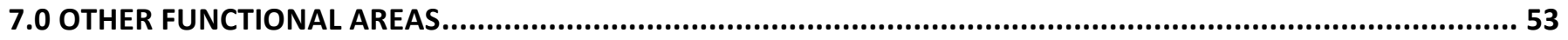

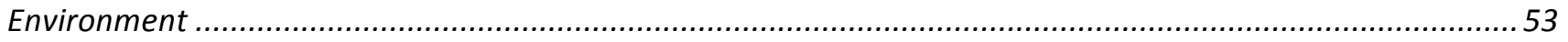

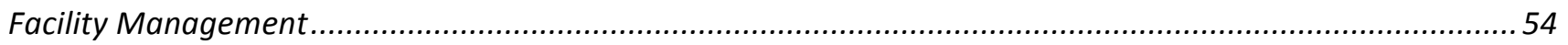

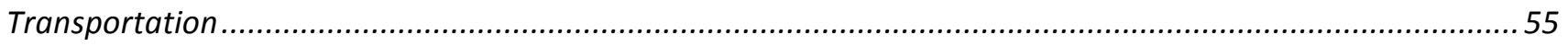

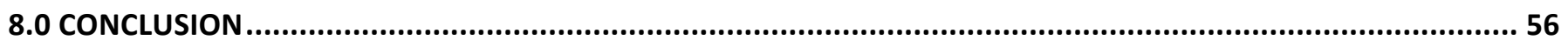

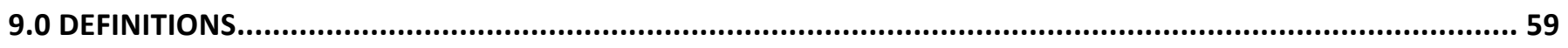

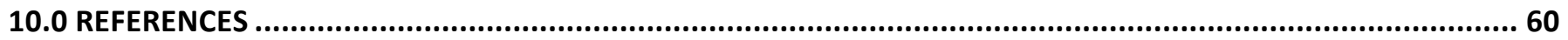




\subsection{Summary}

Data from ITS was analyzed to understand the issues at LLNL and to identify issues that may require additional management attention and these that meet the threshold for reporting to the DOE Noncompliance Tracking System (NTS). In this report we discuss assessments and issues entered in ITS and compare the number and type presently entered in ITS to previous time periods. Issues reported in ITS were evaluated and discussed. The analysis identified two noncompliances that meet the threshold for reporting to the DOE NTS. 


\subsection{Introduction}

All of the data in ITS is analyzed; however, the primary focus of this report is to meet requirements for performance analysis of specific functional areas. The DOE Office of Enforcement expects LLNL to "implement comprehensive management and independent assessments that are effective in identifying deficiencies and broader problems in safety and security programs, as well as opportunities for continuous improvement within the organization" and to "regularly perform assessments to evaluate implementation of the contractor's processes for screening and internal reporting." LLNL has a self-assessment program, described in the document applicable during this time period, ES\&H Manual Document 4.1, that includes line, management and independent assessments. LLNL also has in place a process to identify and report deficiencies of nuclear, worker safety and health and security requirements.

In addition, the DOE Office of Enforcement expects that "issues management databases are used to identify adverse trends, dominant problem areas, and potential repetitive events or conditions" (page 15, DOE Enforcement Process Overview, June 2009). LLNL requires that all worker safety and health and nuclear safety noncompliances be tracked as "deficiencies" in the LLNL Issues Tracking System (ITS). Data from the ITS are analyzed for worker safety and health (WSH) and nuclear safety noncompliances that may meet the threshold for reporting to the DOE Noncompliance Tracking System (NTS).

This report meets the expectations defined by the DOE Office of Enforcement to evaluate implementation of internal processes for screening and reporting, review the assessments conducted by LLNL, analyze the noncompliances found in these assessments, and evaluate the data in the ITS database to identify adverse trends, dominant problem areas, and potential repetitive events or conditions. The report attempts to answer three questions:

Is LLNL evaluating its programs and state of compliance?

What is LLNL finding?

Is LLNL appropriately managing what it finds?

The results from analyzing the deficiencies are presented in accordance with the two primary NTS reporting thresholds for WSH and nuclear safety noncompliances: 1) those related to certain events or conditions and 2) those that are management issues. In addition, WSH noncompliances were also analyzed to determine if any fell under the "other significant condition" threshold.

This report identifies deficiencies that meet the criteria for reporting to the DOE NTS; topics and subtopics that should remain under observation because the number of entries meets the test criteria or because of management concern; and topics and subtopics that are determined to no longer require observation. Topics and subtopics that are identified for continued observation are placed on a "watch list." The purpose of the watch list is for the Performance Analysis and Reporting Section (PARS) of the Contactor Assurance Office to analyze these topics and subtopics in future performance analysis reports. 


\subsection{Assessments Conducted}

\section{Method}

Internal assessments at LLNL include internal independent assessments chartered by the Director's Office, management self-assessments chartered by functional area managers, and line self-assessments chartered by the principal associate director or the associate director (as of the date the data was pulled). DOE and regulatory agencies conduct external assessments. The results of all these types of assessments are entered into ITS. In addition, deficiencies, observations and corrective actions identified during the analysis of events, such as illnesses/injuries and occurrences, are also entered into ITS.

Data on assessments conducted from 2005 through June 2009 were pulled in August using the ITS Basic Assessment Information report. This report includes all assessments performed, whether or not the assessment resulted in a reported observation or deficiency. The report also includes those assessments that have not been assigned a Completion/Final Report Date or a Date Final Report Received in ITS. The ITS allows for assessments to be designated by type. The assessment types have recently been revised and are used in this analysis. For this analysis, the assessment types were binned into the following eight assessing method categories:

- "External" includes the assessment types: external-LSO MAR, external-LSO surveillance and external-other.

- "Internal Independent" includes the assessment types; internal independent, IAOD audit, and LLNL parent org FMA.

- "Management Self" includes the assessment types: management self-functional area, and management self-line.

- "Walkthrough" includes the assessment type: walkthrough.

- "Readiness Review" includes the assessment type: readiness review.

- "Event" includes the assessment types: Event-Illness / Injury CAR, Event-Occurrence and Event-Below ORPS reportable.

- "Quick ITS" includes the assessment type: quick ITS.

- "Other" includes the assessment types: NCAR and Other.

Note that in the previous performance analysis reports, the assessment type walkthrough was not referenced. However, recently this type was reinstated in ITS as one of the assessment type options.

The data was reviewed to determine if the frequency or types of assessments changed during this period. A control chart was used to look at variation of assessment data. It can be considered a way of performing a statistical test, a test whether the process is in a state of control. One control chart was used to analyze variation within internal assessment data referred to as a Frequency control chart. The Frequency control chart in this case plots the internal assessment frequency over quarters.

Along with the frequency of internal assessments, the control charts provide a means to evaluate and compare the number of assessments per quarter to five key elements: 
1) Centerline: the average number of assessments over the time period (mean)

2) Upper warning limit (UWL): two times the standard deviation above the mean

3) Upper Control-limit (UCL): three times the standard deviation above the mean

4) Lower warning limit (LWL): two times the standard deviation below the mean

5) Lower control-limit (LCL): three times the standard deviation below the mean

The key element, UCL, is a common calculation for control charts. In an ideal world, the majority of one's data would lie within the UCL, and a lower control limit (three times the standard deviation below the mean). Standard deviation is a way to measure how far the observations are from their mean. It is also referred to as a measure of spread.

In this report, these elements form the criteria in the common tests.

With these control charts, we are looking for special causes of variation in the data. This type of variation can be found by using common tests.

Two of the common tests are called action limits and are used in this report:

1) One data point falling above the UCL or below the LCL

2) Two consecutive points above the UWL or below the LWL

One point above the UCL or two consecutive points above the UWL is considered an action limit. Theoretically, if a process is 'in-control' then none of the data points will fall outside of the UCL. If data reaches or exceeds an action limit, the assessment data are analyzed further. In addition to the action limits, four other tests of variation or common tests are considered. These are not action limits, but are helpful in identifying which smaller sets of data to be analyzed further:

1) One data point above the UWL

2) Single increase in data points for the quarter in question,

3) Increasing trend for more than one quarter

4) Sustained increase or decrease in the number of data points above or below one standard deviation

The common tests described above are more conservative than those set of decision rules for detecting nonrandom patterns on control charts listed in, "Introduction to Statistical Quality Control" described as:

1) One point plots outside the 3-sigma control limits

2) Two out of three consecutive points plot beyond the 2-sigma warning limits

3) Four out of five consecutive points plot at a distance of 1-sigma or beyond from the center line

4) Eight consecutive points plot on one side of the centerline

\section{Results}

During the 12-month period ending June 2009, LLNL entered 731 management selfassessments, 402 walkthroughs, 4 readiness reviews, 31 internal independent assessments, 108 events, and 9 other assessments. Quick ITS entries are a new feature in ITS and are entered at 
the assessment level, one assessment per PAD, per month. There were eight Quick ITS assessment entries. During this same 12-month period, 171 external assessments were also entered into ITS.

There has been a decreasing trend in the number of internal assessments entered into ITS from the third quarter in 2007, as shown in Figure 1. In fact, during the January-March 2009 and April-June 2009 quarters, LLNL entered the fewest number of internal assessments since the fourth quarter in 2005.

Figure 1. The number of Internal Assessments by Type and Quarter

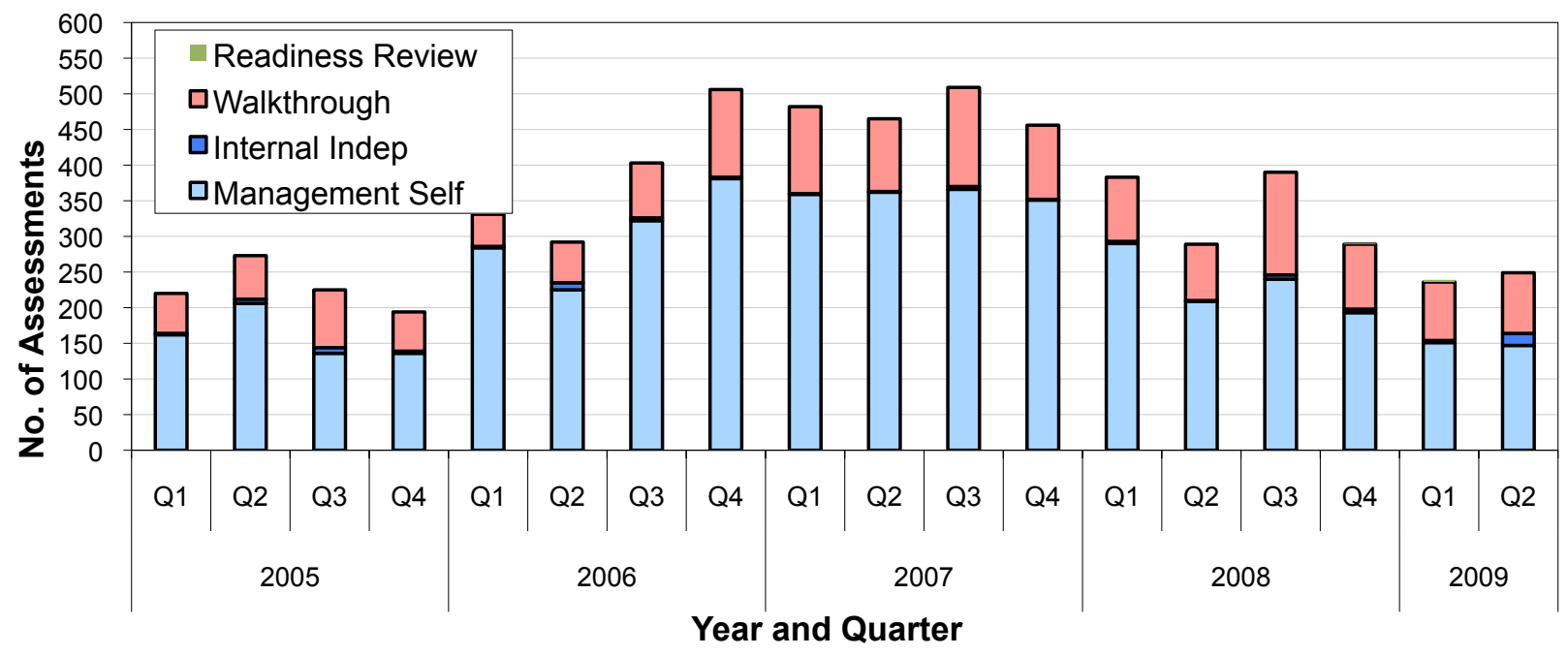


When evaluating the number of assessments conducted each quarter using the process control chart shown in Figure 2, none of the data points are above or below the control limits. In observationally reviewing Figure 2, there appears to be an increasing trend in the number of internal assessments from the first quarter in 2005 to the first quarter in 2007 and a decreasing trend from the third quarter in 2007 to the second quarter in 2009, suggesting that this process has a nonrandom pattern. After testing these potential trends using simple linear regression, both the increasing and decreasing trends were statistically significant ( $\mathrm{p}$-value $<0.01)$, and are shown in Figure 2 as two separate trend lines. This supports the observation that the number of assessments entered into ITS has decreased since the third quarter in 2007.

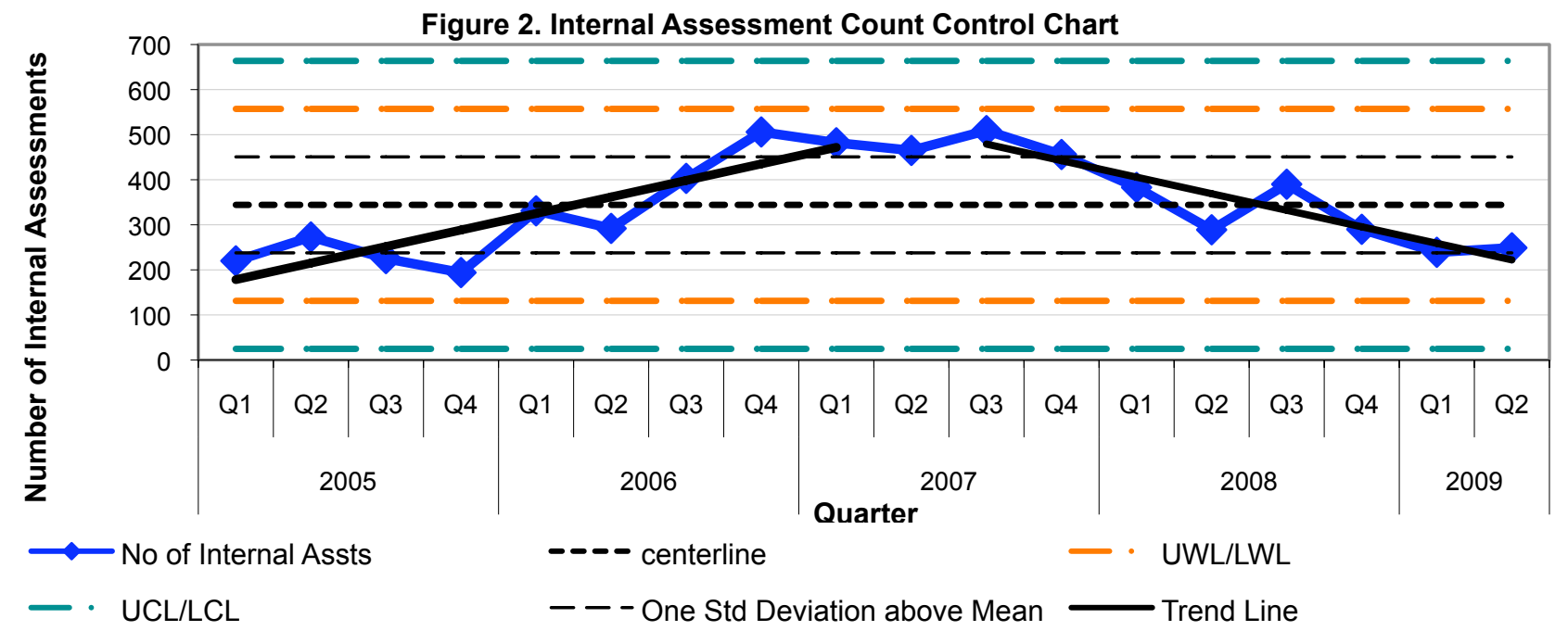

We identified two possible explanations for the reduction. It is possible that some assessments had been completed during 2009, but not entered in ITS. Alternatively, it is possible that the assessment process changed and fewer unique assessments were conducted in 2009.

The data in ITS for the Institutional Assessment Plan (IAP) were pulled. This report provides a list of the planned internal and external assessments. There are 211 internal assessments on the IAP and 95 of these did not have an Assessment Completion/Final Report Date in ITS, which means these assessments were not included in the assessment analysis in Figure 1 and 2. The majority ( $89 \%$ ) of these 95 assessments have due dates after June 30 . Therefore, it is not likely that the assessments have been conducted but not entered in ITS.

Of the 95 assessments without an Assessment Completion/Final Report Date, 39 (41\%) assessments are in functional areas related to nuclear safety and WSH.

Six of these 39 assessments have an Assessment Current Due Date of June 30, 2009 or earlier. These assessments are considered late. Three of these six are the 10CFR835.102 internal audits, as shown in Table 1. Even if the three assessments due prior to June 30 had been completed and entered in ITS, the trend in the number of assessments would still be decreasing.

Of these 39 assessments in functional areas related to nuclear safety and WSH, $29(74 \%)$ have an Assessment Current Due Date in ITS of September 30, 2009, as shown in Table 1. Assuming that the assessments are completed and the ITS assessment entry is updated to include the 
Assessment Completion/Final Report Date, the data will be included in future performance analyses.

Table 1. Assessments in the IAP without an Assessment Completion/Final Report Date

\begin{tabular}{|c|c|c|c|}
\hline Assessment Purpose & Freq. & $\begin{array}{l}\text { Functional Area } \\
\text { (includes Freq.) }\end{array}$ & $\begin{array}{l}\text { Asst Due Dt } \\
\text { (includes } \\
\text { Freq.) }\end{array}$ \\
\hline 10 CFR835.102 Internal Audit Schedule & 5 & Radiation Protection & $\begin{array}{l}6 / 30 / 2009(3) \\
9 / 30 / 2009(2)\end{array}$ \\
\hline $\begin{array}{l}\text { Annual re-certification of waste process for NTS } \\
\text { acceptance }\end{array}$ & 1 & Nuclear Operations & $9 / 30 / 2009$ \\
\hline ESH\&Q Assessment Plan & 2 & WSH & $\begin{array}{l}6 / 30 / 2009(1) \\
9 / 30 / 2009(1)\end{array}$ \\
\hline HS-64 CAP Commitment, IAOD ES\&H Assessment Services & 1 & WSH & $9 / 30 / 2009$ \\
\hline O\&B PAD Assessment Plan for FY09 & 5 & $\begin{array}{l}\text { Occ. Medicine (1), } \\
\text { Nuclear Operations (1), } \\
\text { Packaging and Trans. (1), } \\
\text { WSH (2) }\end{array}$ & $\begin{array}{l}6 / 30 / 2009(1) \\
9 / 30 / 2009(4)\end{array}$ \\
\hline Quality Assurance Department Assessment Schedule & 8 & $\begin{array}{l}\text { QA(4), } \\
\text { WSH (4) }\end{array}$ & $\begin{array}{l}6 / 30 / 2009(1) \\
9 / 30 / 2009(7)\end{array}$ \\
\hline Verify recommendations by FMA, IAOD ES\&HAsst. & 1 & Radiation Protection & $12 / 31 / 2009$ \\
\hline WCI Self Assessment Plan & 3 & $\begin{array}{l}\text { Emergency Mangmt. (1), } \\
\text { QA (1), } \\
\text { WSH (1) }\end{array}$ & $\begin{array}{l}9 / 30 / 2009(2) \\
12 / 31 / 2009(1)\end{array}$ \\
\hline Missing an Assessment Purpose in ITS & 13 & $\begin{array}{l}\text { Occ. Med (4), } \\
\text { QA (1), } \\
\text { Radiation Protection (1), } \\
\text { WSH (7) }\end{array}$ & $\begin{array}{l}9 / 30 / 2009(11), \\
12 / 31 / 2009(2)\end{array}$ \\
\hline
\end{tabular}

Soon after contract transition, discussions began regarding changing the structure and processes for conducting management and independent assessments. Prior to contract transition, most assessments were conducted by the directorates, following requirements in the ES\&H Manual that prescribe the topical areas and frequency for self-assessments, subject matter inspections and facility inspections. This practice resulted in unique entries in ITS for each assessment at each location. The directorate scheduled these assessments and inspections independent of each other. In late 2008, LLNL assigned a central organization to manage most of the facilities and to inspect them. In 2008, responsibility for conducting self-assessments of ESH-related functional/topical areas began to transition from the directorates to the Quality Assurance Office. This, too, would result in fewer unique assessments and inspections being entered into ITS. Figure 2 shows that the change started soon after contract transition as the decreasing trend begins around October 2007 as shown above. 
LLNL evaluates each assessment, to determine whether NTS-reportable deficiencies were identified. This quarter, ten assessment reports were made available for evaluation and assignment of an assessment response owner. These assessments were dated from September 2008 through August 2009. Figure 3 shows the number of assessments, occurrence and analysis reports completed each month and subject to evaluation for noncompliance reporting. A total of 17 assessments are pending a noncompliance evaluation, as shown in Figure 3. The reports pending evaluation are shown in red. These pending assessments have either not been reviewed for WSH and / or nuclear safety noncompliances due to a delay of entry into ITS or the assessment response owner has not been assigned to participate in the reporting determination. Of note are three assessments pending noncompliance evaluation that were issued prior to 2009: the Boiler Safety, the Hearing Conservation, and the Surveillances on Documents and Records assessments. Six of the assessments conducted in 2009 and pending a noncompliance evaluation are related to the 10CFR835.102 audits. It is expected that these assessments will be evaluated during the next quarter. The delay of entry into ITS and evaluation of some assessments may be a programmatic noncompliance for reporting to NTS.

Figure 3. Assessments, Final Occurrence Reports and Analyses Reports Issued Each Month and Their Evaluation Status

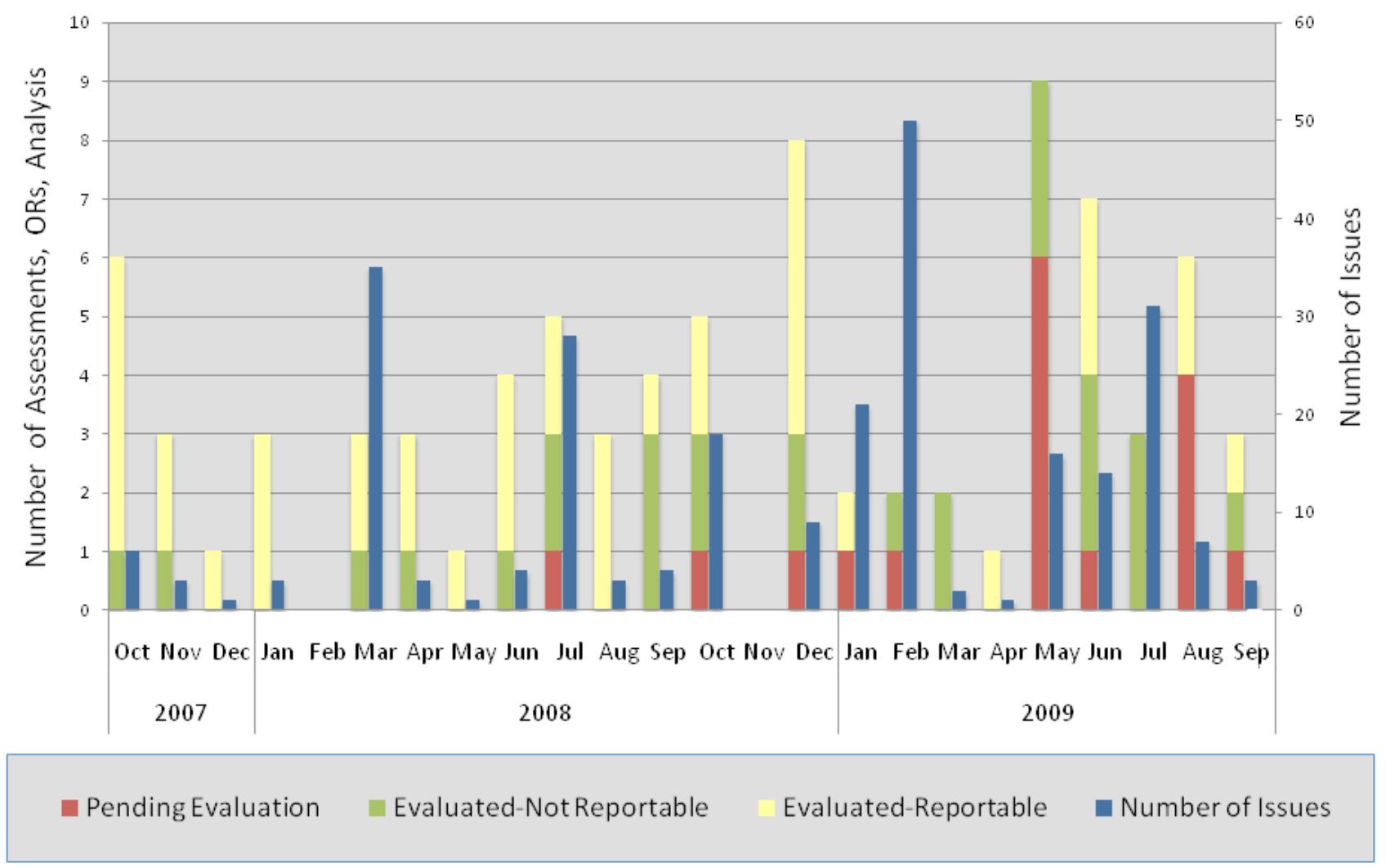




\subsection{Evaluation of Assessments Results}

The average number of issues per assessment conducted since 2006 is five. This quarter the average was four. So far in $2009,49 \%$ of all assessments completed and entered into ITS had at least one issue. A total of 539 observations and 569 deficiencies were entered in ITS from all sources. Figure 4 shows that the number of issues entered into ITS has decreased since the first quarter in 2008. The number of deficiencies has a statistically significant decreasing trend over time ( $p$-value $<0.01$ ). On average for every increase in time (one quarter) the number of deficiencies decreases by 144 , based on simple linear regression. The number of observations, however, is not significantly decreasing over time. This issue as it relates to WSH is discussed further in section 4.2.

The reduced number of deficiencies identified and entered in ITS in this quarter (when compared to previous quarters) may be attributed to improved compliance, a reduction in the number of assessments, a reduction in the scope of assessments, delays in updating data in ITS or other changes.

Figure 4. The Number of ITS Deficiencies and Observations Per Quarter

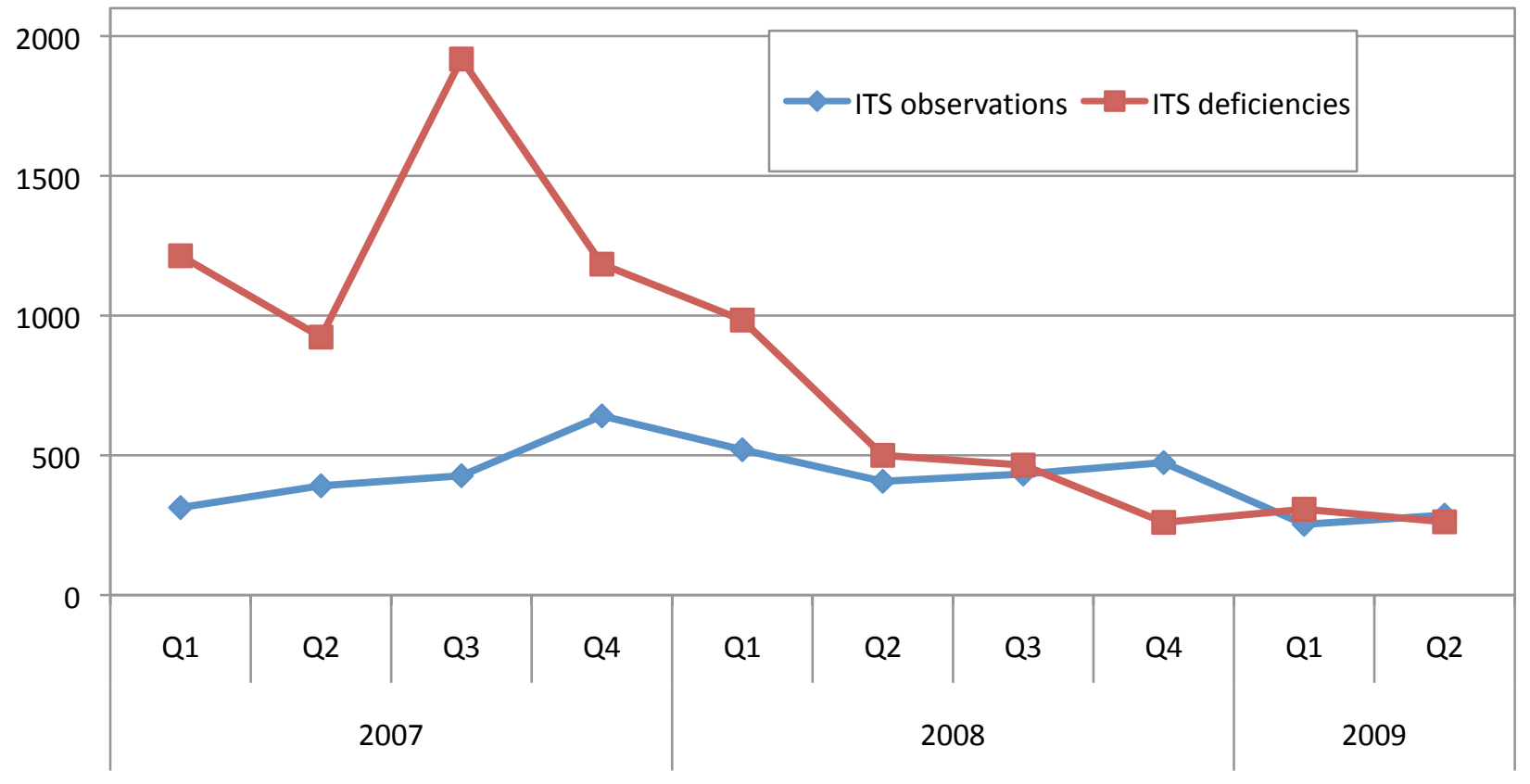


So far in 2009, $52 \%$ of the 569 deficiencies entered into ITS, were marked as WSH site-reportable deficiencies, which is less than 2008 when $62 \%$ were marked as such. In contrast, $17 \%$ were marked as nuclear safety site-reportable deficiencies in 2009, which is more than $2008(7 \%)$, as shown in Table 2. Specifically for WSH, the percentage of site-reportable deficiencies in this quarter is the lowest percentage site-reported in the last six quarters. This issue is discussed further in section 4.2.

Table 2. ITS Deficiencies Entered, Site-reported and NTS-reported Noncompliances

\begin{tabular}{|cccccccc|}
\hline Year & Qrt & $\begin{array}{c}\text { Observations } \\
\text { Entered into } \\
\text { ITS }\end{array}$ & $\begin{array}{c}\text { Deficiencies } \\
\text { Entered into } \\
\text { ITS }\end{array}$ & $\begin{array}{c}\text { WSH Site } \\
\text { Reported } \\
\text { Deficiencies } \\
\text { (Defs) }\end{array}$ & $\begin{array}{c}\text { WSH } \\
\text { Defs } \\
\text { reported } \\
\text { to NTS }\end{array}$ & $\begin{array}{c}\text { NS Site } \\
\text { Reported } \\
\text { Deficiencies }\end{array}$ & $\begin{array}{c}\text { NS Defs } \\
\text { reported } \\
\text { to NTS }\end{array}$ \\
\hline 2008 & Q1 & 520 & 984 & $655(67 \%)$ & $3(<1 \%)$ & $41(4 \%)$ & $3(7 \%)$ \\
\cline { 2 - 7 } & Q2 & 407 & 500 & $284(57 \%)$ & $4(1 \%)$ & $44(9 \%)$ & $2(4 \%)$ \\
\hline Q3 & 433 & 465 & $300(65 \%)$ & $6(2 \%)$ & $39(8 \%)$ & $3(7 \%)$ \\
\hline 2009 & Q1 & 253 & 260 & $175(67 \%)$ & $2(2 \%)$ & $40(15 \%)$ & $1(4 \%)$ \\
\hline & 286 & 307 & $190(62 \%)$ & $5(3 \%)$ & $60(20 \%)$ & $1(2 \%)$ \\
\hline
\end{tabular}

Nine $(2 \%)$ of the WSH and nuclear safety site-reportable deficiencies were reported to the DOE NTS so far in 2009, counting a NUC/WSH noncompliance report as a report for nuclear safety and a report for WSH. This ratio is consistent with 2008 when $2 \%$ of site reported deficiencies were reported to the DOE NTS. 
It does appear that the number of nuclear safety noncompliance reports has decreased in the recent three years. As shown in Figure 5, it appears that there is a relationship between the number of occurrence reports and the number of nuclear safety noncompliance reports; as the number of occurrence reports increases so does the number of nuclear safety noncompliance reports. This relationship was found to be statistically significant and the number of occurrence reports is positively correlated with the number of noncompliance reports ( $p$-value $<0.05$ ). LLNL has also experienced a recent decrease in the number of occurrences, specifically in occurrences related to nuclear safety.

Figure 5. The Relationship between Nuclear Safety Noncompliance Reports and Occurrence Reports

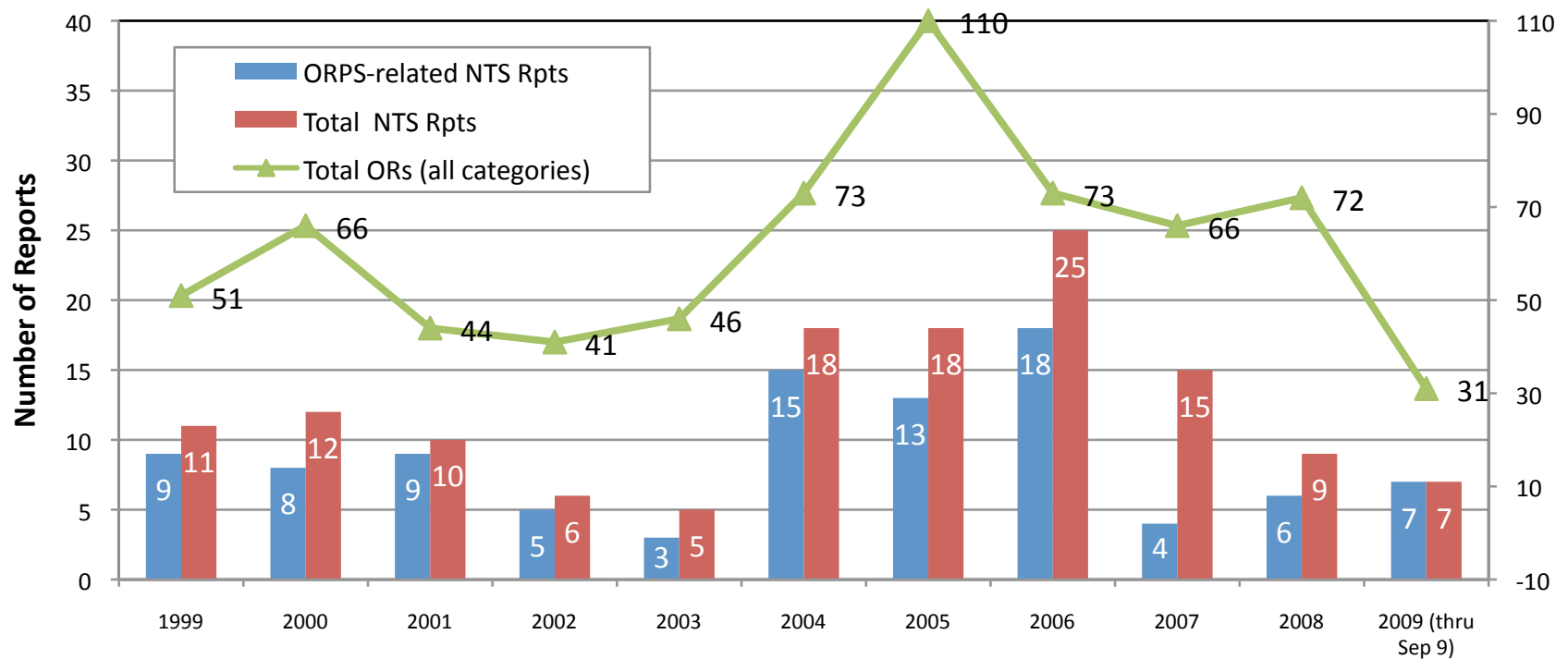

This reduction was investigated to ensure it reflected actual performance and not a reduction in reporting. Historically, most of the nuclear safety-related occurrences have been for safety basisrelated issues in LLNL's Hazard Category 2 and 3 nuclear facilities. It is believed that, as the facility safety basis documents have been updated and workers have become more familiar with these new documents, there have been fewer potential inadequacies in documented safety analyses and fewer violations of Technical Safety Requirements. This improved compliance has resulted in fewer occurrence reports and noncompliance reports. 


\subsection{Evaluation of Noncompliances}

This section evaluates the identified noncompliances for specific safety areas that may need attention. LLNL requires that all worker safety and health and nuclear safety noncompliances be tracked as "deficiencies" in the Issues Tracking System (ITS). As each deficiency is entered into ITS, it is assigned a compliance code, functional area, topic and subtopic. The previous performance analysis report analyzed safety areas by the compliance code, class, heading and titles. However, since then, these terms have changed to functional areas, topics and subtopics.

\subsection{Noncompliances Related to Events or Conditions}

\section{Method}

DOE expects that noncompliances associated with certain Occurrence Reporting and Processing System (ORPS) reporting criteria be reported, regardless of the severity of the noncompliance. LLNL uses the NTS reporting thresholds specified in the DOE Enforcement Process Overview, Appendices A and B and described in ES\&H Manual, Document 4.4, "Identifying, Reporting, and Tracking Noncompliances with Nuclear Safety and Worker Safety and Health Requirements."

Occurrences are reviewed promptly for NTS-reportable WSH and nuclear safety noncompliances, as they are reported into the ORPS. The initial review is based on the description of the occurrence. However, after the occurrence is further characterized and analyzed for causes, additional information may be available that identifies noncompliances that should be reported. The Contractor Assurance Office works with the directorate point of contacts to make this determination.

\section{Worker Safety and Health Results}

LLNL submitted 32 occurrence reports to ORPS from January to September 2009. Each occurrence was evaluated for possible noncompliances. Of these occurrence reports, nine were of the type that met a NTS reporting threshold for WSH:

(1) "Unauthorized Work On Lighting Switch In Building 453 Office" [NA-LSO-LLNLLLNL-2009-0006]

(2) "NIF Target Positioner Nose Cone Pivoted, Pinning Worker's Hand" [NA-LSOLLNL-LLNL-2009-0010]

(3) "Worker Fractures Ankle After Stepping Off Paved Path Near Building 271" [NALSO-LLNL-LLNL-2009-0014]

(4) "LLNL Flatbed Truck Accident with DOE Rental Car" [NA-LSO-LLNL-LLNL-20090017]

(5) "Near Miss Involving Non-authorized Energized Work in Building 691" [NA-LSOLLNL-LLNL-2009-0019] 
(6) “Worker Sustains Ankle Fracture After Slipping Off Curb While Entering Vehicle in Parking Lot South of Building 661" [NA-LSO-LLNL-LLNL-2009-0022]

(7) "Non-Energized Electrical Cable Cut Without Proper Energy Isolation" [NA-LSOLLNL-LLNL-2009-0027]

(8) "On Site Vehicle Accident by Building 242 Results in Fatality" [NA-LSO-LLNL-LLNL2009-0028]

(9) "Discovery of Modified Exterior 2nd Floor Hand Rail System at Building 432" [NALSO-LLNL-LLNL-2009-0029]

Four of these nine occurrence reports were identified to have a WSH noncompliance(s) associated with the event and these noncompliances have been submitted to the NTS:

(1) NTS--LSO-LLNL-LLNL-2009-0006, “Unauthorized Work On Lighting Switch In Building 453 Office"

(2) NTS--LSO-LLNL-LLNL-2009-0008, “Near Miss Involving Non-authorized Energized Work in Building 691"

(3) NTS--LSO-LLNL-LLNL-2009-0012, “Near Miss-Non-Energized Electrical Cable Cut Without Proper Energy Isolation"

(4) NTS-LSO-LLNL-LLNL-2009-0017, “Discovery of Modified, Exterior, 2nd Floor Hand Rail System at Building 432"

Four occurrences did not involve a WSH noncompliance. Two of the four noncompliance evaluations have been completed and documented in ITS using the noncompliance evaluation field. These two were related to occurrences of ankle fractures. Two occurrences are pending the noncompliance evaluation entry into ITS: the occurrence of the nose cone pinning the worker's hand and the traffic accident involving an LLNL flatbed truck. The fifth occurrence report related to the on-site vehicle accident is pending a noncompliance evaluation until after issuance of the final root cause analysis.

\section{Nuclear Safety Results}

Of the 32 occurrence reports submitted to ORPS from January to September 2009, four met a NTS reporting threshold for nuclear safety:

(1) "Building 153 Evacuated Due to Toxic Gas Monitoring System Alarm" [NA--LSOLLNL-LLNL-2009-0023]

(2) “Operational Emergency Not Needing Further Classification - Roadside Vegetation Fire At Site 300" [NA-LSO-LLNL-LLNL-2009-0025]

(3) "Operational Emergency Not Needing Further Classification - Wildland Fire At Site 300" [NA-LSO-LLNL-LLNL-2009-0025]

(4) "Movement Of Combustible Fuel In Proximity Of Facility Not Analyzed Per Safety Basis" [NA-NVSO-LLNV-LLNV-2009-0002]

Each of these occurrences was evaluated for noncompliances with nuclear safety requirements and for reportability to the DOE Noncompliance Tracking System. Based on the results of these evaluations, the four occurrence reports were dispositioned as follows: 
(1) The toxic gas alarm reported in NA--LSO-LLNL-LLNL-2009-0023 was determined by causal analysis to have been a spurious event. No noncompliance with DOE

Nuclear Safety Requirements existed, and the event was therefore not reportable to the NTS.

(2) The fire reported in NA-LSO-LLNL-LLNL-2009-0025 was an operational emergency determined to not be the result of LLNL activities. No noncompliance with DOE Nuclear Safety Requirements existed, and the event was therefore not reportable to the NTS.

(3) The fire reported in NA-LSO-LLNL-LLNL-2009-0026 was an operational emergency for which no noncompliance with DOE Nuclear Safety Requirements existed. The event was therefore not reportable to the NTS.

(4) The failure to conduct the analysis required by the Joint Actinide Shock Physics Experimental Research (JASPER) facility safety basis constituted an NTS-reportable noncompliance with the DOE Quality Assurance Rule (10 CFR 830, Subpart A). LLNL submitted report NTS-NSO--LLNV-NTS-2009-0001 to the Noncompliance Tracking System on September 4, 2009.

\subsection{Management Issue Noncompliances}

Management issue noncompliances are defined as repetitive noncompliances, programmatic issues and intentional violations or misrepresentations. One goal of this analysis is to identify a programmatic issue through a review of multiple deficiencies within the same subtopic or topic. Secondarily, the analysis may identify a previously overlooked repetition of the same type of deficiency. A programmatic problem generally involves some weakness in administrative or management controls or their implementation, to such a degree that a broader management or process control problem exists. A repetitive problem is generally two or more different events that involve substantially similar conditions, locations, equipment, or individuals. Repetitive problems tend to be narrower in scope than programmatic problems.

\section{Method}

Analysis included a three-step process of first looking at the data as a whole to identify visual variations; second, performing statistical tests of the sets of data gleaned from the first step, and third, evaluating this remaining set of data by reviewing the context of the noncompliances, such as, discovery method, location in terms of facility, the compliance code, and the description of the noncompliance.

Data from 2005-June 2009, was extracted from ITS on August 12, 2009 using the ITS Basic Issue Report. 
The process for analyzing this data was to review the deficiencies by quarter, looking for groupings with large numbers of deficiencies, observed changes in the number of deficiencies, or other observations that look different from what is expected. Then, if the numbers appeared to be of interest, two control charts were created for the subtopic and/or topics within the seven functional areas related to WSH and nuclear safety listed above.

A control chart can be considered a way of performing a statistical test, a test whether the process is in a state of control. Two control charts were used to look at variation within the subtopics / topics for the six functional areas; a control chart referred to as the Frequency control chart and one referred to as the Rate control chart. The Frequency control chart plots the deficiency frequency per quarter along with the number of assessments within a quarter whereas the Rate control chart plots the number of deficiencies per assessment within a specified quarter.

Along with the frequency of deficiencies or deficiencies per assessment, these control charts consist of three key elements:

1) Centerline: the average number of deficiencies or average deficiencies per assessment over the three years (mean)

2) Upper warning limit (UWL): two times the standard deviation above the mean

3) Upper Control-limit (UCL): three times the standard deviation above the mean

The UCL is a common calculation for control charts. In an ideal world, the majority of one's data would lie within the UCL, as defined above and a lower control limit (three times the standard deviation below the mean). Standard deviation is a way to measure how far the observations are from their mean. It is also referred to as a measure of spread. In this analysis, the primary concern was the number of deficiencies above the two upper limits, the UWL and UCL.

The number of deficiencies in a quarter cannot be below one or zero, and in many cases the LWL and LCL would have been below one or zero had it been incorporated in the control charts. Therefore, the following two other key elements, which are typically part of a control chart are not shown in the charts in this analysis:

4) Lower warning limit ( $L W L)$ : two times the standard deviation below the mean

5) Lower control-limit ( $L C L)$ : three times the standard deviation below the mean

With these charts, we are looking for special causes of variation. This type of variation can be found by using common tests. Two of the common tests are called action limits:

1) One data point falling above the UCL or below the LCL

2) Two consecutive points above the UWL or below the LWL

A point above the UCL or two consecutive points above the UWL is considered an action limit. Theoretically, if a process is 'in-control' then none of the data points will fall outside of the UCL. If data reaches or exceeds an action limit, a more detailed examination of the specific deficiencies will occur in order to determine if repetitive, programmatic or systemic weaknesses exist that may be reportable to the DOE Noncompliance Tracking System. If the subtopic or topic meets one of the test criteria above, but has already been reported to NTS, further explanation will not be provided. 
The four final tests of variation or common tests are not considered action limits:

1) One data point above the UWL

2) Single increase in data points for the quarter in question,

3) Increasing trend for more than one quarter

4) Sustained increase or decrease in the number of data points above or below one standard deviation

These are used to identify subtopics or topics that may be of interest and will be further analyzed. If further analysis concludes that the subtopic or topic does not require reporting to management or NTS and analyzed for root cause, the subtopic or topic will be placed on the watch list. The purpose of the watch list is for the Performance, Analysis and Reporting Section (PARS) of the Contactor Assurance Office to watch certain subtopics or topics and include them in future quarterly reports. Those subtopics or topics with deficiencies that make the watch list in this quarterly analysis will automatically be analyzed next quarter using control charts by the PARS.

The common tests described above are more conservative than those set of decision rules for detecting nonrandom patterns on control charts listed in, "Introduction to Statistical Quality Control" described as:

1) One point plots outside the 3-sigma control limits

2) Two out of three consecutive points plot beyond the 2-sigma warning limits

3) Four out of five consecutive points plot at a distance of 1-sigma or beyond from the center line

4) Eight consecutive points plot on one side of the centerline

Although these decision rules are also considered in the control chart analysis, the six common tests described above are meant to detect topics/ subtopics that should be place on the watch list to watch for nonrandom patterns detected by the four decision rules described above.

Because issues are usually identified by assessments, if there is a change in the subtopics, topics or number of assessments in a quarter, it will affect the number of issues identified. Therefore, the variation in number of assessments conducted in any one quarter and entered in ITS may be substantial and may significantly affect the number of deficiencies identified. If a data point falls above the UWL or UCL on the Frequency control chart, but below the UWL or UCL on the Rate control chart, this suggests that the point outside of one of the limits may have been due to an increase in the number of assessments on that subtopic or topic during that quarter. This information is considered in the analysis. 


\section{Results}

The data comprised 17,587 deficiencies identified under all functional areas, with identification dates in 2005, 2006, 2007, 2008 and 2009 through June. The data also included 98 deficiencies without a designated functional area. Of the 17,587 deficiencies, 13,270 were designated in the following six WSH and nuclear safety functional areas: emergency management, nuclear operations, occupational medicine, packaging and transportation, radiation protection and worker safety and health. Figure 6 displays deficiencies across all functional areas and highlights those related to WSH (red) and nuclear safety (green). Topics in the safety functional areas were analyzed using control charts and the results are discussed below.

Figure 6. Number of Deficiencies in 2009 Per Functional Area

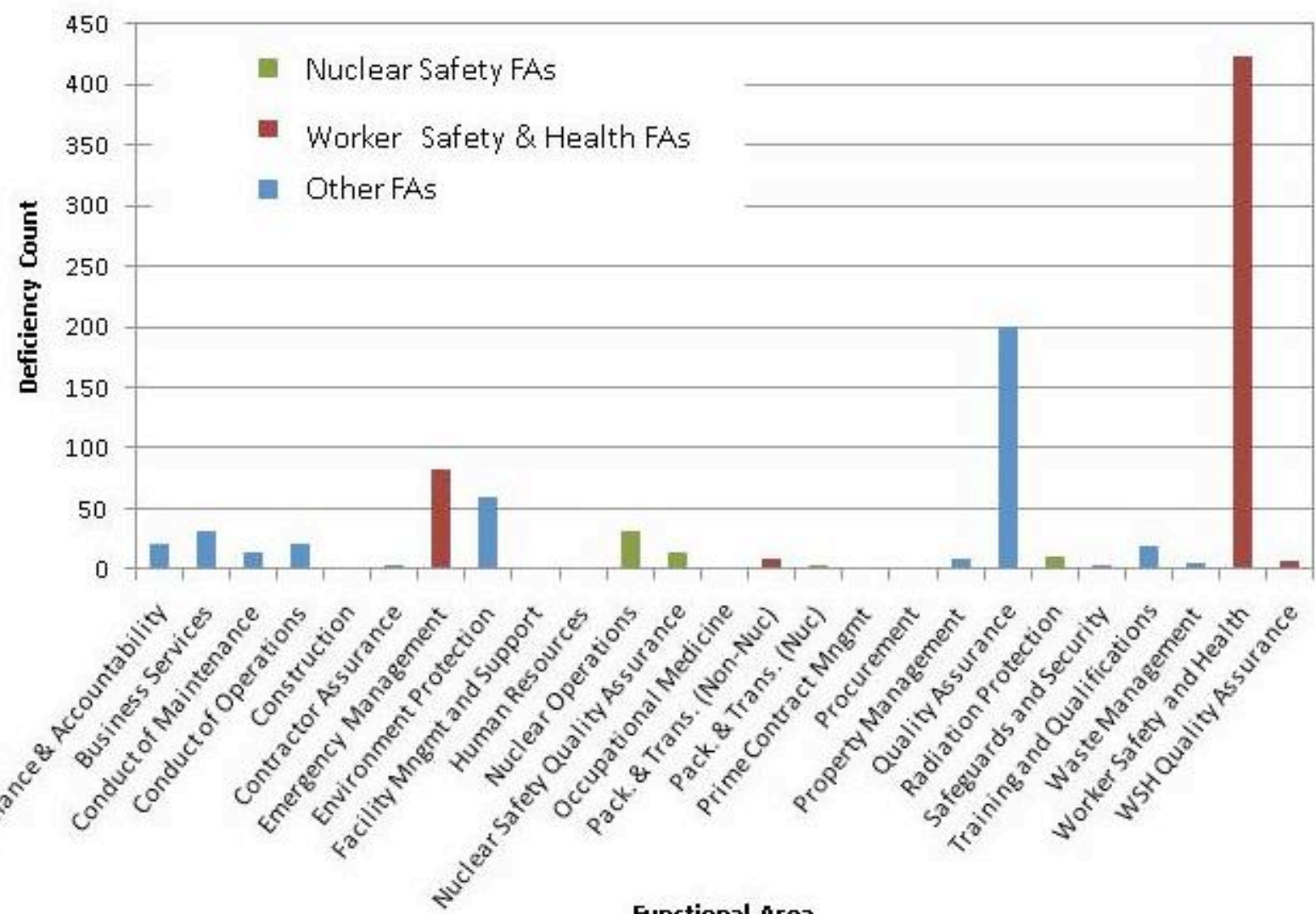

Functional Area

Deficiencies categorized within the quality assurance (QA) functional area are also discussed in this report. However, a QA deficiency does not always have a nuclear safety nexus. When the QA deficiency is related to nuclear safety, the nuclear safety screening question should be marked, "yes." Of the 17,587 deficiencies in the data set, 2,922 were identified as QA deficiencies; however, only 251 of the 2,922 (9\%) were marked as nuclear safety noncompliances using the screening question in ITS. 


\section{Worker Safety and Health Results}

Based on the frequency of deficiencies entered in the last 18 quarters, no subtopics or topics revealed the need for control charts this quarter. Based on this, analysis using control charts was conducted at the functional area level for emergency management and WSH.

\section{Emergency Management Functional Area Deficiencies}

The identification and reporting of issues in the emergency management functional area have been decreasing over time. For the period of 2005-2009, more than $87 \%$ of these issues were identified prior to 2008, as shown in Figure 7. In 2005, 18\% of issues were identified in Fire Hazard Analysis assessments. In 2006, 45\% of the issues were found during the worker safety and health baseline assessments. In 2007, 15\% of issues were a result of the LLNS due diligence walkdowns performed prior to transition.

The majority of emergency management issues since 2005 are deficiencies (95\%). Ninety seven percent $(97 \%)$ of emergency management deficiencies are categorized under the topic, fire safety, and $94 \%$ of these are categorized within three subtopics, evacuation of occupants, fire safety and fire suppression, as shown in Figure 7.

Figure 7. Emergency Management Issues/Deficiencies by Subtopic and Year

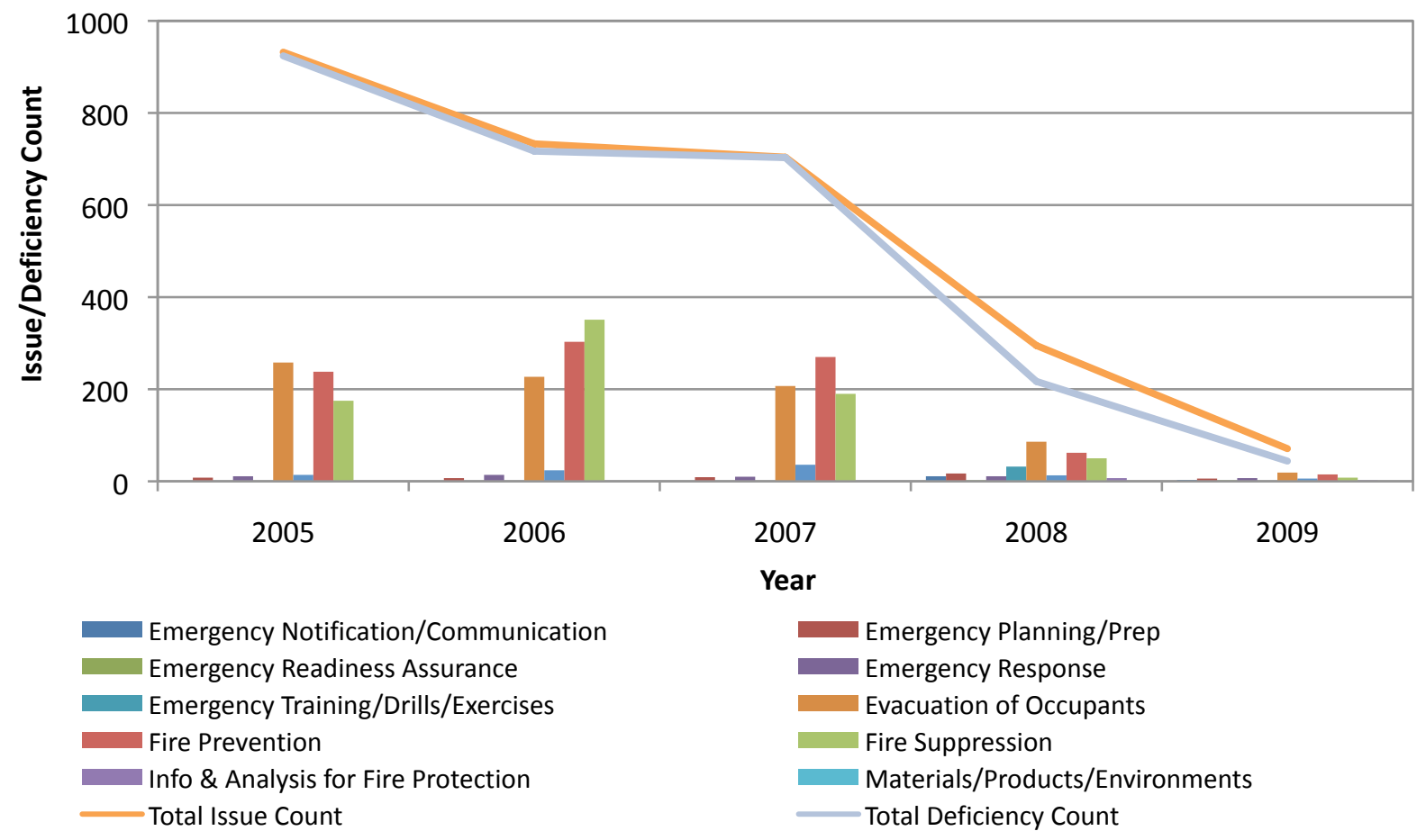


Based on the control chart analysis for emergency management deficiencies, none of the data points are above the UCL. There is a decreasing trend over time in emergency management, deficiencies ( $p$-value $<0.05$ ). On average, for every increase in time (one quarter) the emergency management deficiencies decrease by 11 .

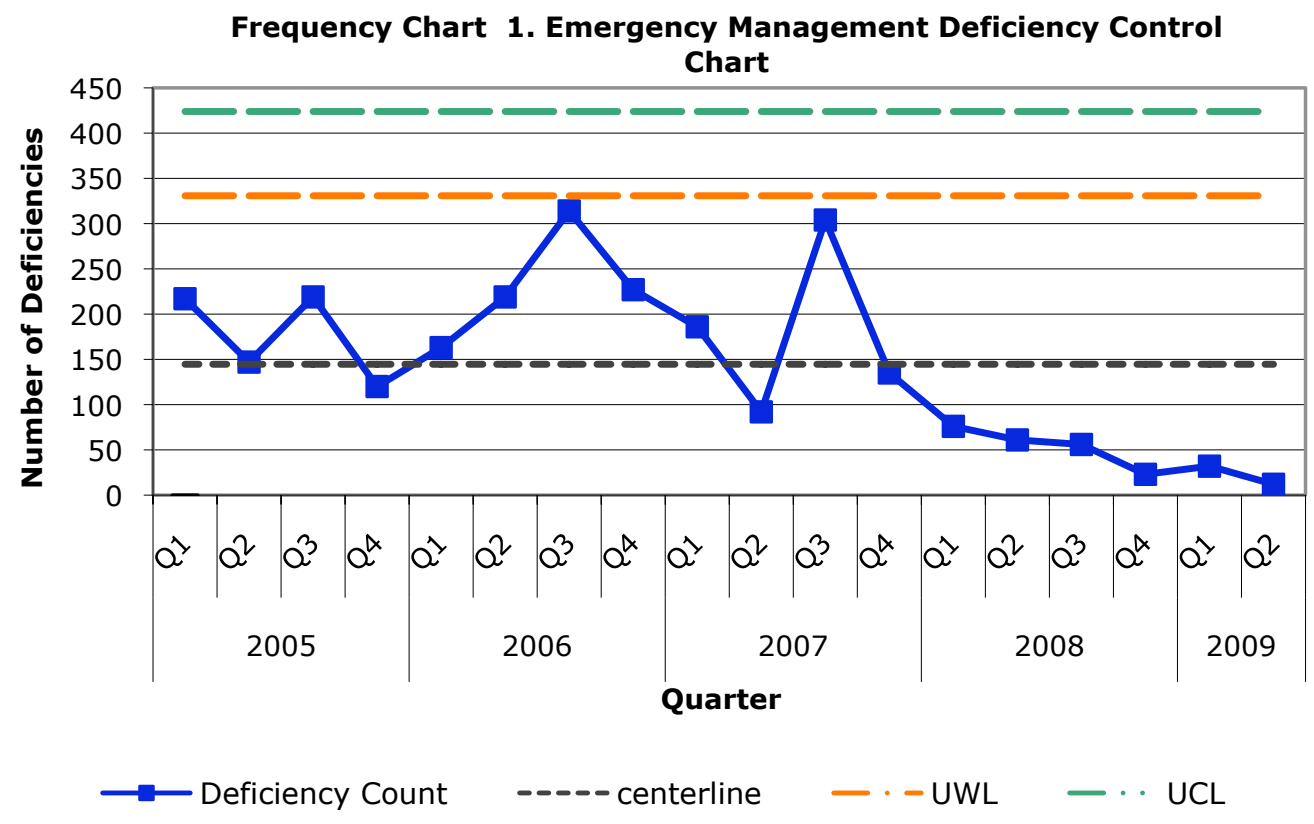




\section{WSH Functional Area Deficiencies}

Since 2005, 95\% of WSH site-reported deficiencies have been categorized under three topics: electrical, industrial hygiene (IH) and industrial safety (IS). The number of deficiencies in the seven topics under the WSH functional area are shown in Figure 8. For all topics, there was a reduction in the number of deficiencies identified in 2008 and 2009 to date. As shown in Figure 8 , there was an increase in IS deficiencies in 2007 . Forty percent (40\%) of the IS deficiencies entered into ITS in 2007 are ladder/scaffolding deficiencies mainly from the assessment in response to the 2006 ladder occurrence. A noncompliance report was submitted to the DOE NTS in December of 2006 regarding these deficiencies with the title, "Employee fall from ladder at trailer 6179 results in multiple fractures." Twenty two percent (22\%) of IS deficiencies in 2007 were seismic related from many different sources, one of these sources being the LLNS due diligence walkdowns performed prior to transition. The majority of IH deficiencies in ITS since 2005 are categorized as four subtopics, hazard communication $(36 \%)$, general $\mathrm{IH}(21 \%)$, chemical storage $(16 \%)$ and emergency equipment and response $(14 \%)$.

Figure 8. Worker Safety and Health Deficiencies by Topic and Year

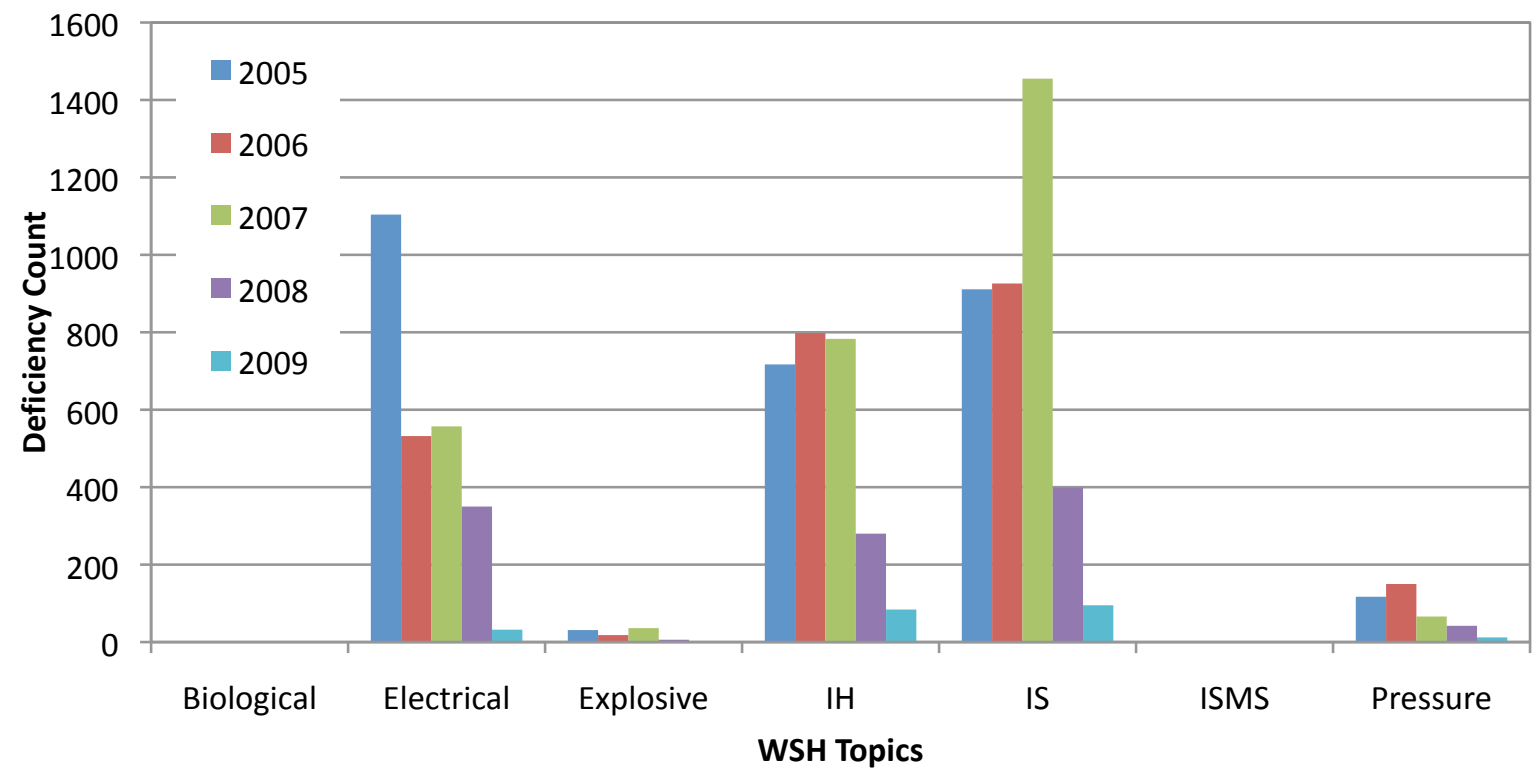


Overall, the number of deficiencies entered into ITS and marked as WSH deficiencies by either the screening question in ITS or the compliance code have been decreasing since the third quarter in 2007, as shown in Frequency chart 2. This decreasing trend is statistically significant using simple linear regression ( $\mathrm{p}$-value $<0.01$ ). On average, for every increase in time (one quarter) the WSH deficiency count decreased by 35 (see the linear trend line in Frequency chart 2). Since the first step of analysis is to visually review the number of deficiencies to identify subtopics / topics that appear to have increased numbers, an overall reduction in the number of WSH deficiencies would explain why no WSH related subtopics or topics were identified as needing control chart analysis this quarter.

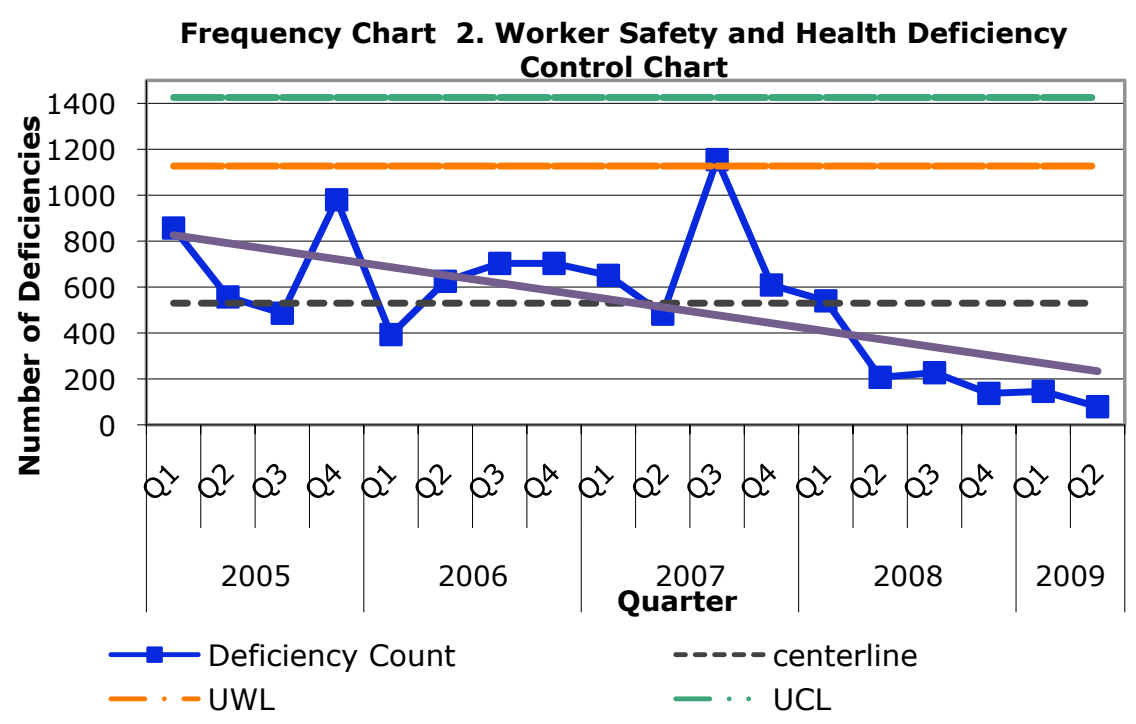


WSH Functional Area Deficiencies and Observations

In order to determine whether the number of WSH related issues in ITS have decreased in addition to the number of deficiencies, the WSH observations were also analyzed. Frequency chart 3 shows that WSH observations increased from the third quarter of 2006 to the fourth quarter in 2008, and then decreased through the second quarter in 2009. A data point is above the UCL in the fourth quarter of 2008. Thirty four percent (34\%) of the WSH observations entered into ITS in the fourth quarter of 2008 are a result of the LLNL beryllium work pause/review. The majority (45) of these were from the National Ignition Facility and Photon Science Principal Directorate. Fifteen percent (15\%) of the WSH observations from the fourth quarter of 2008 were from the NIF 2008 Annual Walkabout in which different IWSs are reviewed.

Some clarification is helpful in understanding Frequency chart 3. It appears to indicate that there were no observations in 2005. In fact, there are significantly more observations in ITS prior to 2008 than are shown in Frequency chart 3. Prior to the recent changes in the ITS business rules, observations were not assigned a functional area, topic or subtopic. Therefore, after the rules changed and when old observations were mapped to functional areas using the compliance codes, 3,741 observations identified prior to 2008 were not mapped to any functional area. Now observations with issue significance 1-4 and a status beyond draft-new require functional area, topic and subtopic. This is one reason we see a recent increase in WSH observations in Frequency chart 3.

Frequency Chart 3. Worker Safety and Health Observation Control Chart

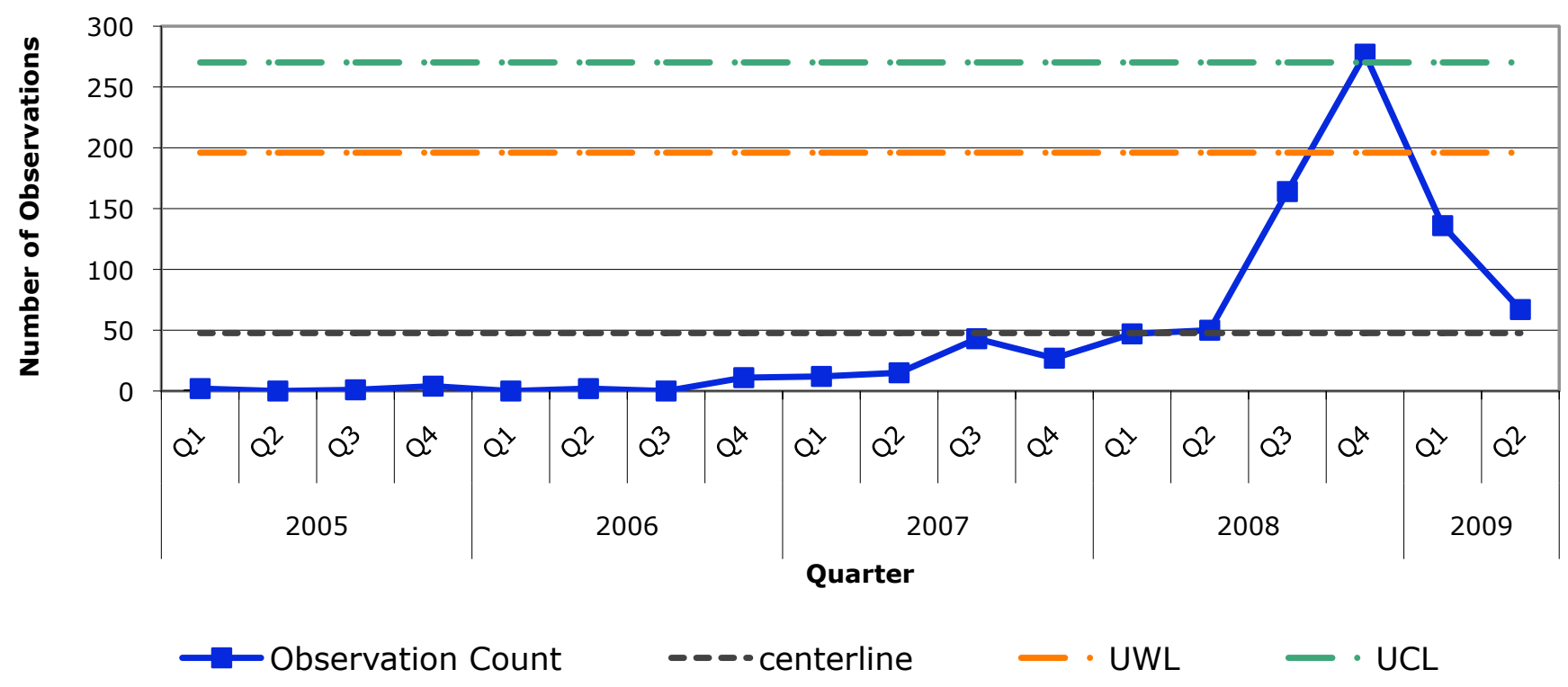


In order to determine whether the decrease in the WSH deficiency counts is related to the increase in the WSH observation counts, these two were compared to one another and the correlation of the two was tested using the Pearson Correlation Test. Figure 9 displays the relationship between the WSH deficiencies and observations. For example, one point represents the count of both the WSH deficiencies and observations for a particular quarter between 2005 and 2009. For example, the point on the far right of Figure 9 represents 1,155 deficiencies and 43 observations entered into ITS in the third quarter of 2007. Observationally it appears that as the WSH deficiency count decreases the WSH observation count increase and vice versa. This theory was confirmed using the Pearson Correlation Test. There is significant, negative correlation between the WSH deficiency and observation counts (rho $=-0.59$, p-value $<0.05$ ). In the more recent quarters, WSH deficiencies have decreased, but WSH observations have increased.

Figure 9. The Relationship between WSH Deficiencies and Observations

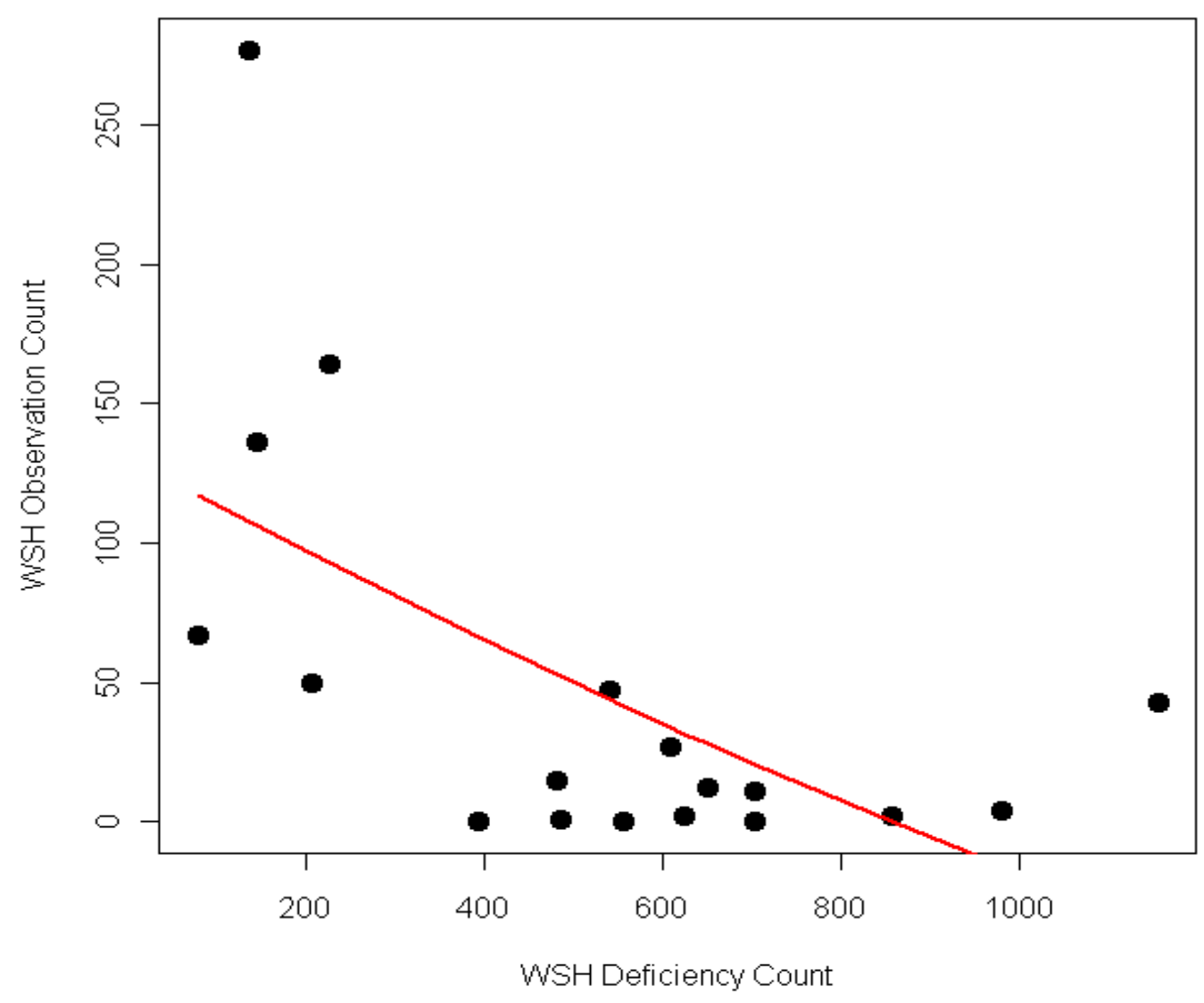


The most commonly used WSH subtopics shown in Figure 8 were also analyzed to see if the same relationship exists between the deficiencies and observations for these subtopics. Figure 10 displays the topics, electrical, hazard communication and seismic deficiency and observation counts over the last four years. The two quarters in 2009 were not included in this figure since it wouldn't compare to the four quarters used in each year. Although the number of observations are low (the secondary axis in Figure 10), observationally the number of electrical, hazard communication and seismic deficiencies are decreasing over time and the number of electrical, hazard communication and seismic observations are increasing over time.

\section{Figure 10. WSH Common Subtopical Deficiencies and Observations}

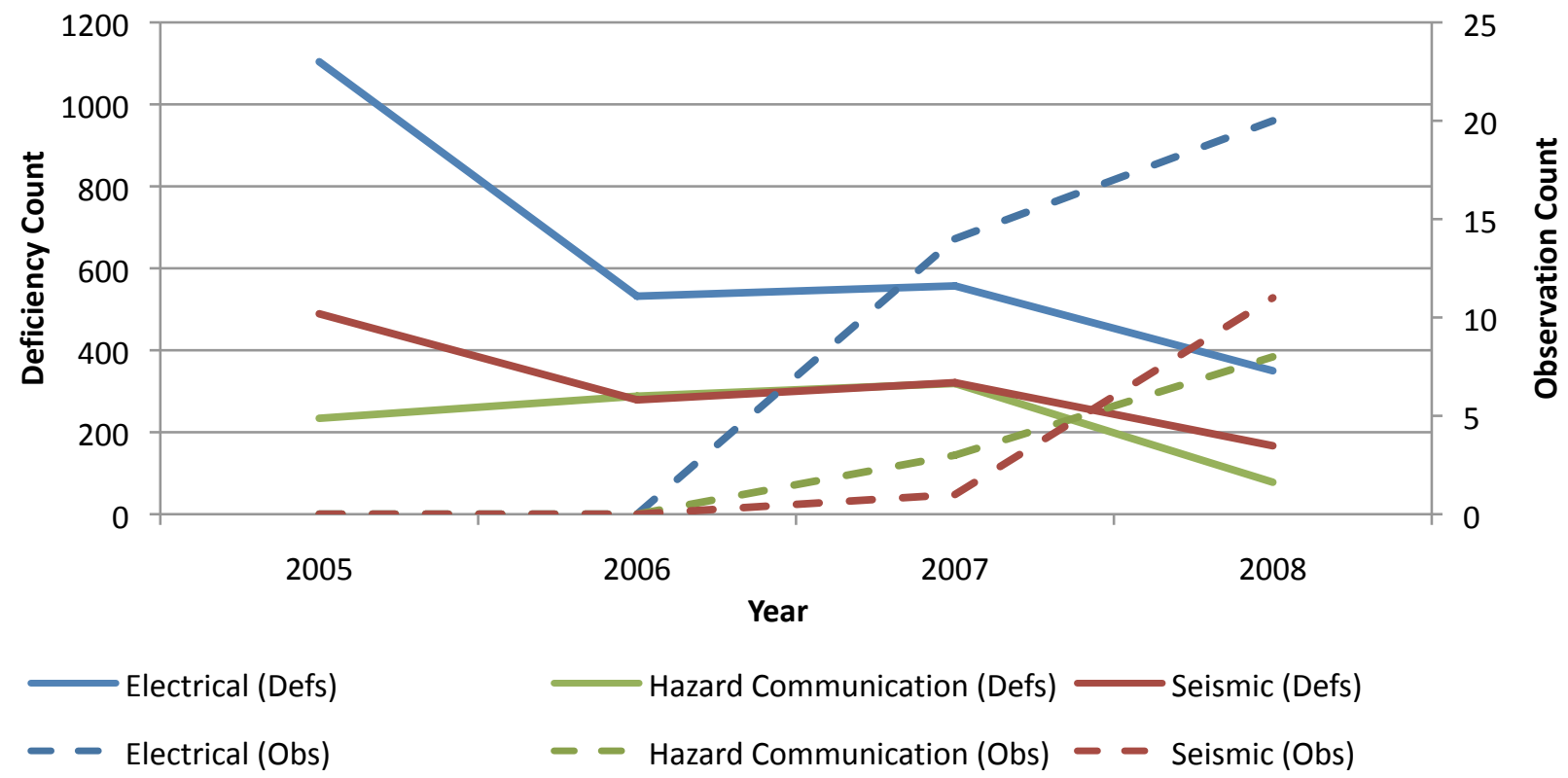

One possible explanation for the decrease in WSH deficiencies and the increase in WSH observations is that WSH deficiencies are being incorrectly categorized as observations. In order to determine if this is the reason for the relationship between WSH deficiencies and observations, a five percent sample was taken of all WSH observations entered into ITS since $2005(n=858)$. This sample $(n=43)$ included only observations from 2007-2009, the years that the increase in WSH observations began. These 43 WSH observations were reviewed by an Industrial Safety Engineer and an Industrial Hygienist. The reviewers reported that 35\% of the sample was determined to have been incorrectly categorized as observations and should have been categorized as deficiencies with 10 CFR 851 enforceable requirements, such as those described in the LLNL Worker Safety and Health Program. Twenty six percent $(26 \%)$ of the issue descriptions did not provide enough information to determine whether it was properly categorized as an observation or whether it should have been categorized as a deficiency. Thirty five percent $(35 \%)$ of the WSH observations were determined to have been properly categorized as observations.

If the deficiencies counts for 2007-2009 were increased by 35\% to account for those deficiencies that were incorrectly categorized, the WSH deficiency counts are still observationally decreasing over time. When tested using a linear regression, the decreasing trend was still statistically significant ( $\mathrm{p}$-value $<0.01$ ). Therefore, although some WSH deficiencies were incorrectly 
categorized as observations, this does not account for the entire decreasing trend in WSH deficiencies. When the WSH deficiencies and observations were plotted together, there is still a statistically significant decreasing trend ( $\mathrm{p}$-value $<0.05$ ). Another possible explanation for the decrease in WSH deficiencies and observations could be due to the decrease in assessments, as discussed in section 2.0.

Subtopics Placed on the Watch List in Previous Performance Analysis

The following five WSH issue subtopics were placed on the watch list in the previous quarterly report and are analyzed this quarter:

- confined space,

- continuous air monitoring,

- electrical,

- ladders/scaffolding,

- laser

\section{Confined Space}

This quarter there were no confined space deficiencies entered into ITS, as shown in Frequency chart 4. This subtopic was placed on the watch list in the previous performance analysis report to see if additional deficiencies would be entered in the fourth quarter of 2008, possibly creating an increase in these type of deficiencies over three consecutive quarters. However, only one deficiency was entered in the fourth quarter of 2008. Therefore there was no continued increase in confined space deficiencies and this subtopic will be removed from the watch list.

Frequency Chart 4. Confined Space Deficiency Control Chart

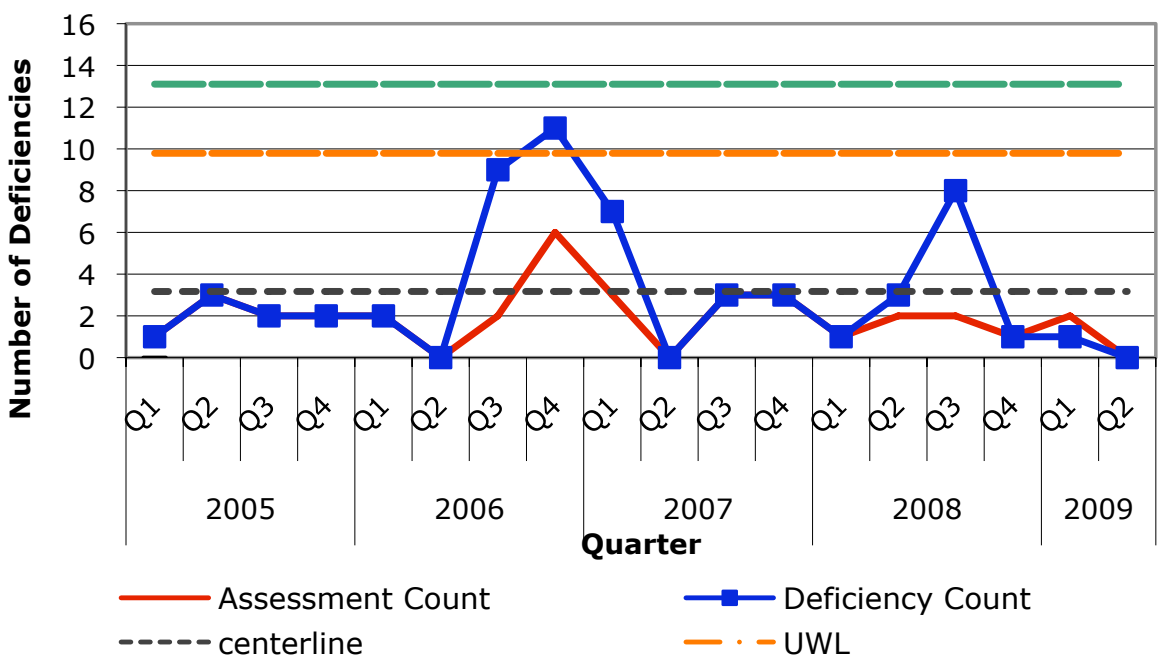




\section{Continuous Air Monitoring}

This quarter there were no continuous air monitoring deficiencies entered into ITS, as shown in Frequency chart 5 . This subtopic was placed on the watch list in the previous performance analysis report because in the review of these deficiencies a common test was met, a point above the UWL in the second quarter of 2008. However since then, there have only been two continuous air monitoring deficiencies entered into ITS. Since a common test was not met for the two quarters not previously analyzed (the first and second quarters in 2009), this subtopic will be removed from the watch list.

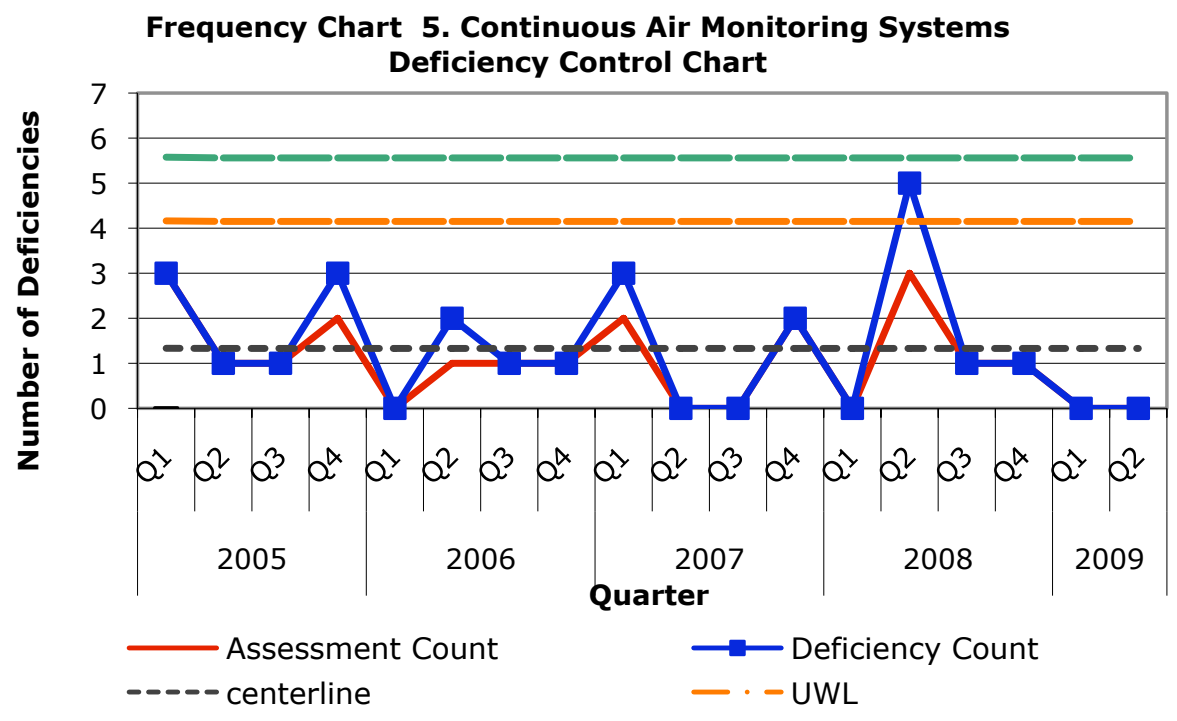




\section{Electrical}

This quarter there were only nine electrical deficiencies entered into ITS, as shown in Frequency chart 6. In fact, since the first quarter in 2008 the number of electrical deficiencies has decreased from 232 to nine in the second quarter of 2009. Considering the last 18 quarters, LLNL identified and entered this quarter the least number of electrical deficiencies into ITS in three years, as shown in Frequency chart 6 . So far in 2009, only 32 electrical deficiencies have been entered into ITS. Also, 2009 had the fewest number of assessments that reported electrical deficiencies compared to the previous three years, with only 36 in ITS so far for 2009.

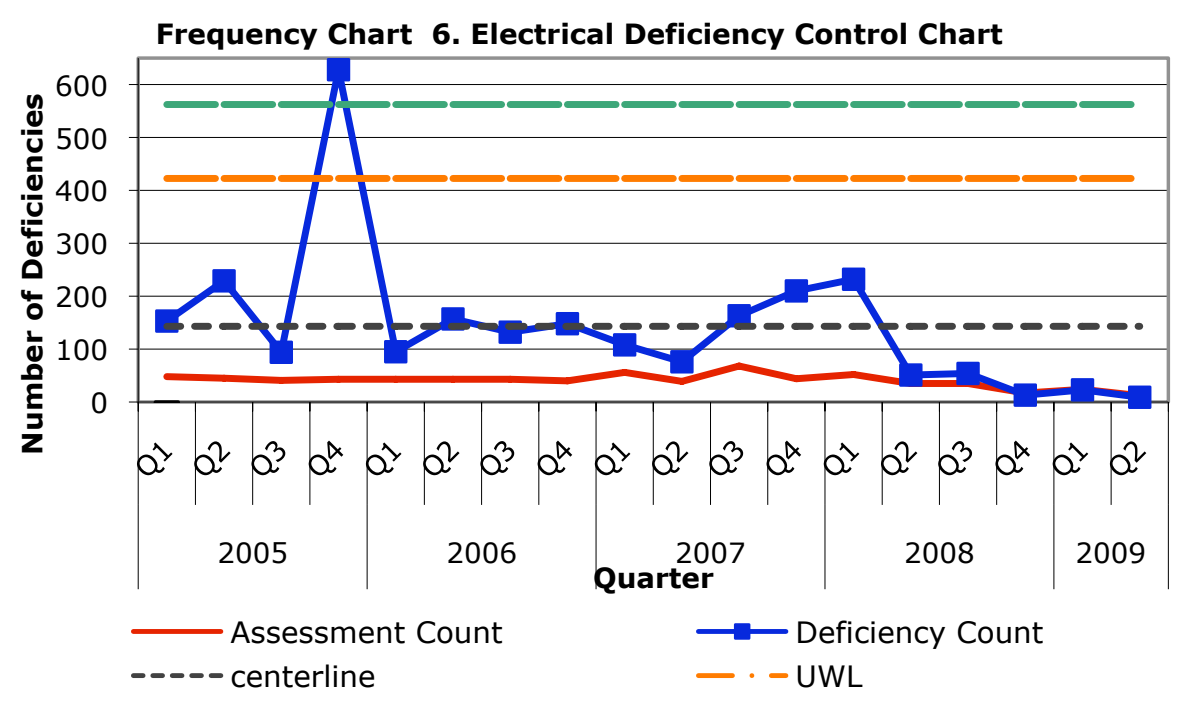

Electrical deficiencies were originally put on the watch list in early 2008 due to an increase in deficiencies from the second to the fourth quarter in 2007. LLNL has reported two electrical safety programmatic noncompliances to the DOE NTS since 10 CFR 851 became enforceable. The first, related to the 10 CFR 851 gap analysis was reported in May of 2007. The effectiveness review completed for these noncompliances identified new noncompliances that were recently reported to the DOE NTS in September 2009, NTS-LSO-LLNL-LLNL-2009-0016, "Programmatic Noncompliances related to the Implementation of LLNL Electrical Safety Program."

Although none of the common tests described in the methods section were recently met in 2009, due to management's request to continue overseeing electrical safety, this subtopic will remain on the watch list for future quarters. 
Ladders/Scaffolding

This quarter there were only three ladder/scaffolding deficiencies entered into ITS, as shown in Frequency chart 7.

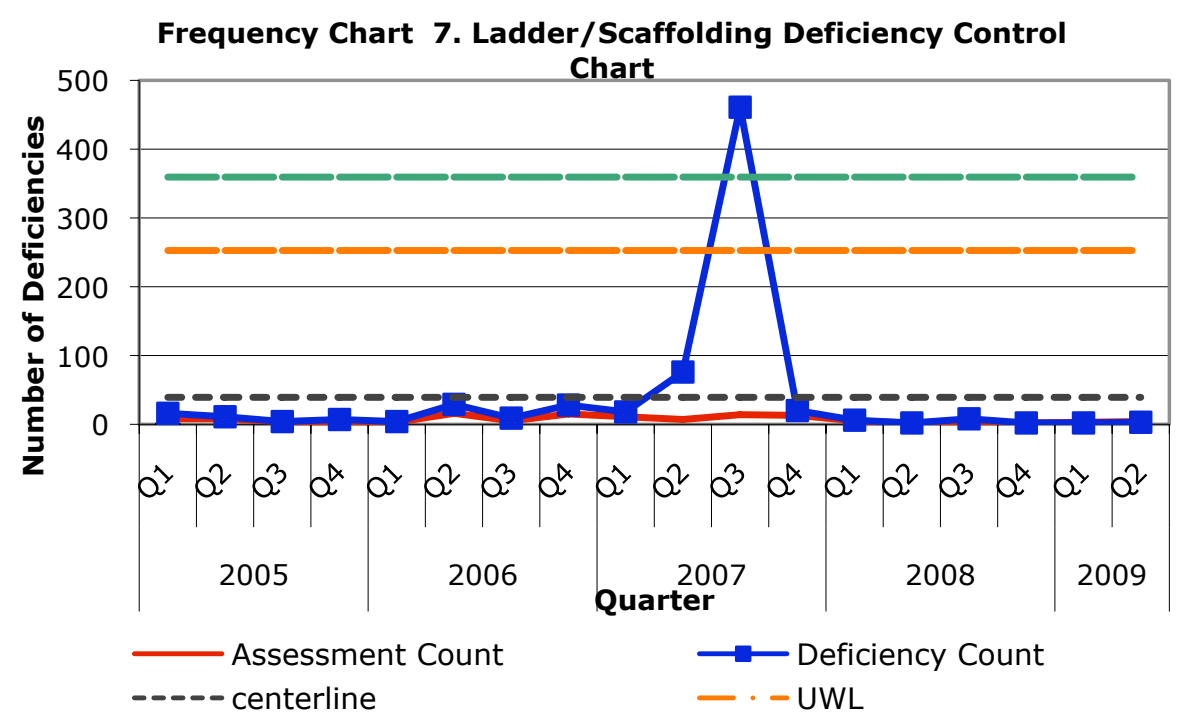

As discussed in all previous performance analysis reports, ladder/scaffolding safety had a significant increase in the number of deficiencies in the third quarter of 2007, as shown in Frequency chart 7. This significant increase is due to the findings from a comprehensive assessment on fixed ladders, an action from the ladder event in 2006. In the fourth quarter of 2006 a noncompliance report was submitted to the NTS for the ladder event titled, "Employee fall from ladder at trailer 6179 results in multiple fractures." Forty three ladders/ scaffolding deficiencies have been entered into ITS since the significant amount of ladder/scaffolding deficiencies were entered into ITS in the third quarter of 2007. The majority of these 43 were categorized as, Not otherwise specified; description of deficiency required (14) and Portable ladder and/or step stool is not inspected, stored, and/or maintained as required (18). Of the 41 deficiencies entered into ITS since the third quarter of 2007, 18 of the 43 ladder/scaffolding deficiencies are owned by the National Ignition Facility and Photon Science Principal Directorate, with the majority of these deficiencies identified in Building 581.

None of the common tests described in the methods section were met for ladders / scaffolding deficiencies, and due to the minimal number of deficiencies entered into ITS, this will be taken off of the watch list. 
Laser

During this quarter the number of laser deficiencies increased from five in the first quarter of 2009 to eight, as shown in Frequency chart 8.

Frequency Chart 8. Laser Deficiency Control Chart

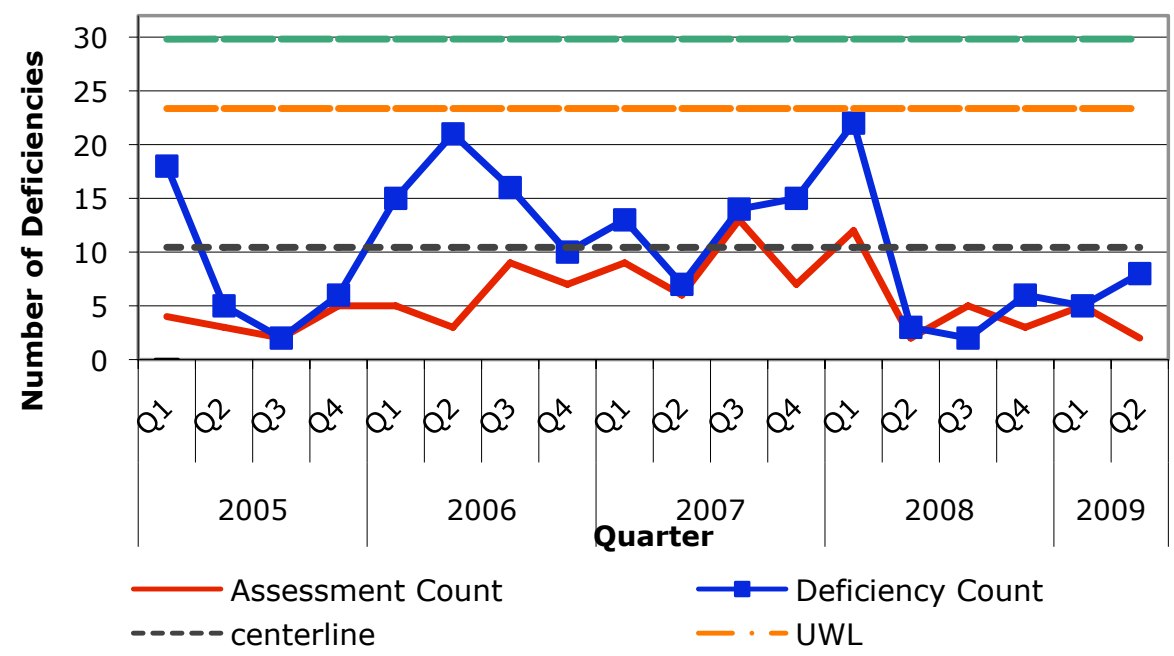

These eight deficiencies are from two different assessments, “2009 PLS Laser Safety Audits” and "MSAL-031 / GS Lasers Assessment FY0904," were categorized among four different compliance codes and were all assigned an issue significance three. These deficiencies are listed in Table 3.

Table 3. Description of the Eight Laser Safety Deficiencies from the Second Quarter of 2009

\begin{tabular}{|cl|}
\hline Frequency & $\begin{array}{l}\text { Deficiency Description } \\
\text { Laser specific warning signs are not accurate, are missing, and/or are not conspicuously displaced } \\
\text { where they will best serve to warn onlookers. }\end{array}$ \\
\hline $\mathbf{2}$ & $\begin{array}{l}\text { Safety interlocks and/or access warning systems in laser controlled areas are (1) not present } \\
\text { where required; or (2) not maintained/tested; or (3) bypassed without approval; or (4) } \\
\text { inoperative. }\end{array}$ \\
\hline $\mathbf{2}$ & $\begin{array}{l}\text { Work with laser optical fibers was not done according to procedures and/or procedures were not } \\
\text { instituted to prevent inadvertent personnel exposure. }\end{array}$ \\
\hline $\mathbf{1}$ & Not otherwise specified; description of deficiency required. \\
\hline
\end{tabular}

This subtopic was originally put on the watch list due to an increase in deficiencies in the first quarter of 2008. In the second and third quarter of 2008 the number of deficiencies decreased; however, since the number of laser deficiencies appears to be increasing since the third quarter in 2008, this subtopic will remain on the watch list to monitor the data for the performance analysis report. At this time, the collection of deficiencies do not constitute a significant or a systemic or programmatic noncompliance reportable to the DOE NTS. 


\section{Nuclear Safety Results}

Nuclear safety deficiencies are categorized as radiation protection, safety basis, criticality safety, nuclear packaging and transportation, and quality assurance. There have been no new deficiencies categorized as criticality safety since January 2008 so this topic will not be analyzed using a control chart. Criticality safety deficiencies; however, are discussed in this report to see if the thirteen posting and labeling deficiencies that were miscategorized as criticality safety, an issue discussed in the performance analysis for the January-March 2008 quarter, were recategorized under a different and more appropriate topic.

Based on the frequency of deficiencies by functional area in the most recent 18 quarters, three of the four nuclear safety related functional areas will be analyzed using control charts:

- nuclear operations,

- quality assurance,

- radiation protection

The following two issue subtopics were placed on the watch list in the previous performance analysis report requiring continued analysis this quarter and will be discussed in the context of the radiation protection functional area:

- radiation protection-design and control,

- radiation protection-posting/labeling

As discussed in the sections below, the analysis for nuclear safety did identify two functional areas and two subtopics with increased deficiencies in this quarter. 


\section{Nuclear Operations Functional Area}

During this quarter there were 16 deficiencies categorized in the nuclear operations functional area, as shown in Frequency chart 9. Since there have only been 70 nuclear operations deficiencies entered into ITS since 2005, it is expected that 16 entered during one quarter would cause a point to be above the UCL. This is an action limit, so this functional area will be further examined for a potential programmatic/systemic noncompliance reportable to the DOE NTS.

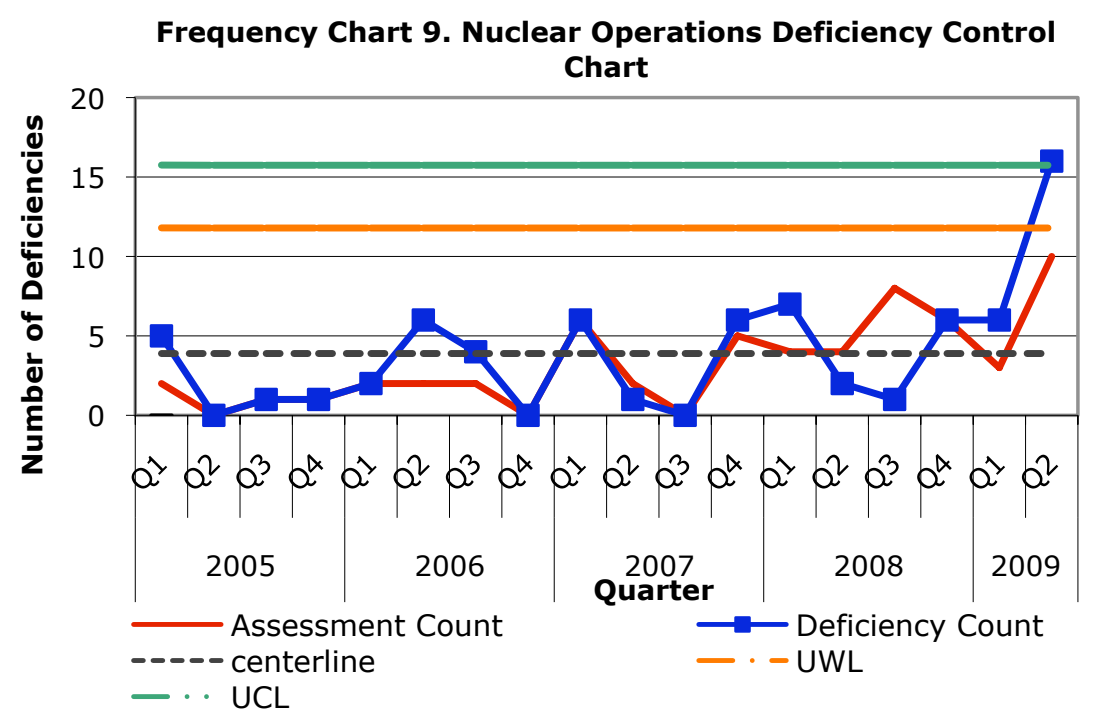

Within the nuclear operations functional area there are seven topical areas: configuration management, criticality safety, nuclear facility startup/restart, nuclear material operations, nuclear training, safety basis analysis, design and documentation and system engineering.

Fourteen of the 16 deficiencies categorized in the nuclear operations functional area in the second quarter of 2009 were categorized as the safety basis analysis, design and documentation topic, and are discussed below. 
Nuclear Operations-Safety Basis Analysis, Design and Documentation

There is also a point above the UCL for the safety basis analysis, design and documentation topic as show in Frequency chart 10. As noted earlier, the UCL is an action limit that triggers a more detailed examination of the specific deficiencies in order to determine if repetitive, programmatic or systemic weaknesses exist that may be reportable to the DOE Noncompliance Tracking System.

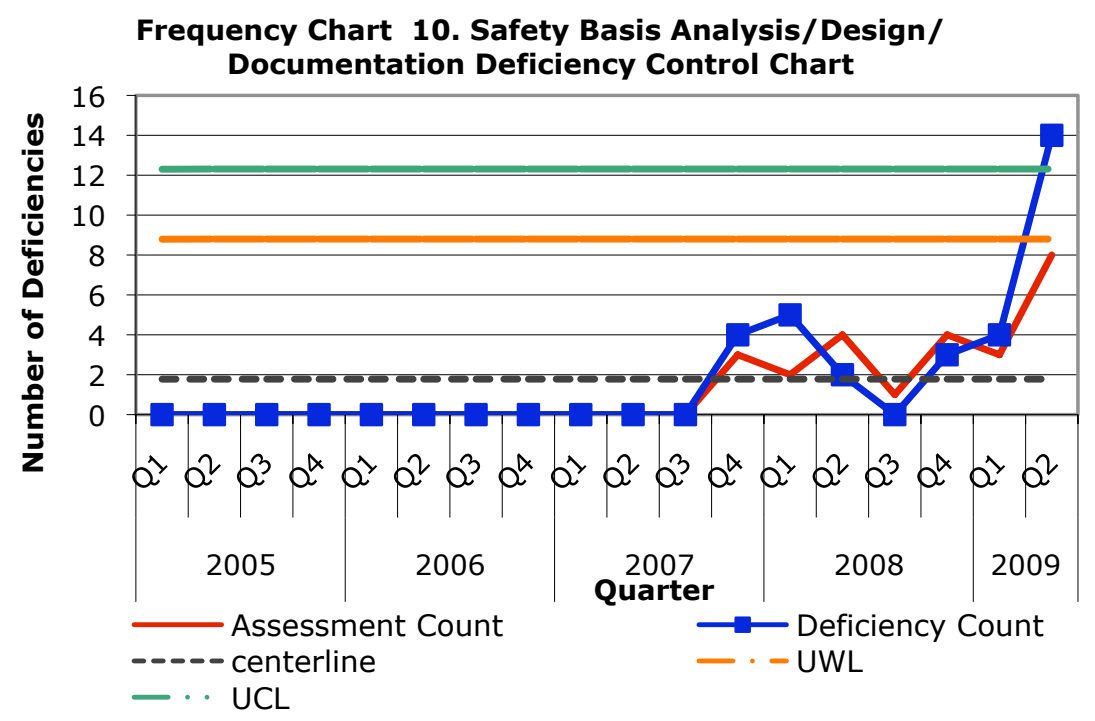

The point is above the UCL because there were 14 safety basis deficiencies entered in the second quarter of 2009. There are three different sources of the 14 safety basis deficiencies:

1. Nine deficiencies were identified by a single LLNL management assessment [Ref: LLNLAR-412863, "2009 USQ Assessment Report in Preparation for CDNS Review" (April 22, 2009)]. LLNL performed this assessment in preparation for a comprehensive external assessment of the LLNL Unreviewed Safety Question (USQ) process, to be conducted later in 2009 by the NNSA Chief of Defense Nuclear Safety (CDNS) and the NNSA Livermore Site Office (NNSA-LSO).

2. Three deficiencies were identified by NNSA-LSO in its Monthly Assessment Reports (MARs) during the period April to June 2009.

3. Two deficiencies were identified by the directorate and reported to the DOE ORPS.

Both deficiencies from the occurrence reports have been reported to the DOE Noncompliance Tracking System in the following reports:

1. $\quad$ NTS-LSO-LLNL-LLNL-2009-0007, "Rapid Pressure Pulse During Treatment Activities Leads to Loss of Radioactive Material" (submitted 5/01/2009)

2. NTS-NSO--LLNL-NTS-2009-0001, "Movement of Combustible Fuel in Proximity of Facility Not Analyzed per Safety Basis" (submitted 9/04/2009) 
Three of the 14 deficiencies were assigned compliance codes (not ".00" codes), with two categorized as "Failure to implement the DOE-approved USQ process in a situation where there is a temporary or permanent change in a facility or in procedures described in an existing DSA," and the other categorized as "Failure to implement the DOE-approved USQ process in a situation where there is a test or experiment not described in an existing DSA."

Ten of the 14 deficiencies were categorized as issue subtopic, "Unreviewed Safety Questions," although the specific USQ deficiencies cover a variety of topics related to LLNL implementation of the USQ process. Nine of the USQ-related deficiencies came from the 2009 USQ Assessment Report, the tenth was related to the safety basis deficiency identified in occurrence report NA-NVSO-LLNV-LLNV-2009-0002 and reported to the DOE NTS in NTS-NSO--LLNV-NTS-20090001. None of the USQ-related deficiencies were assigned to a specific facility. Because the deficiencies were identified during the one assessment and had not been identified previously, they are not considered repetitive.

Table 4 lists the 12 deficiency descriptions discovered by assessments, including the source of the deficiency (note that Table 4 does not include the occurrence-related deficiencies).

Table 4. Assessment-Identified Safety Basis Deficiencies from the Second Quarter in 2009

\begin{tabular}{|cll|}
\hline \multicolumn{1}{|c|}{ Source } & Deficiency Description \\
& $\begin{array}{l}\text { Building 332 (B332) Surveillance Requirements Procedure (SRP), SRP-B332-4.1.2 / 4.1.5 does } \\
\text { not include Increment } 1 \text { loft and Increment } 3 \text { basement floors on grade beneath safety class } \\
\text { and Safety Significant System, Structures, and Components (SSCs) in the annual visual } \\
\text { inspection. }\end{array}$ \\
\hline MAR (May 2009) & $\begin{array}{l}\text { The B334 TSR IP failed to identify the need to revise the two } \\
\text { Administrative Control Procedures (ACPs) that implement B334 TSRs. }\end{array}$ \\
\hline MAR (June 2009) & Site 300 858 Forensic Receival Facility Safety Basis Change Inappropriately Authorized \\
\hline USQ Asst Prep for CDNS & $\begin{array}{l}\text { FSCM.1-1: Facility-specific USQ Procedures Contain Instructions in Conflict with the } \\
\text { Provisions of ES\&H Manual Document 51.3 (7) }\end{array}$ \\
\hline USQ Asst Prep for CDNS & UD.3-1 Inadequate Evaluation and Discernible Increase (39) \\
\hline USQ Asst Prep for CDNS & $\begin{array}{l}\text { FSCM.2-1 Facility-specific Procedures Utilize Disallowed USQ Terminology and Definitions } \\
\text { Inconsistent with ES\&H Manual Document 51.3 (10) }\end{array}$ \\
\hline USQ Asst Prep for CDNS & $\begin{array}{l}\text { UEC.1-1 Facility Work Permits with Unclear Bases or Improper Disposition of the USQ Process } \\
\text { (14) }\end{array}$ \\
\hline USQ Asst Prep for CDNS & $\begin{array}{l}\text { UEC.2-1 Document Control Processes Do Not Establish that All Procedure Changes Enter the } \\
\text { USQ Process (22) }\end{array}$ \\
\hline USQ Asst Prep for CDNS & $\begin{array}{l}\text { UEC.2-2 Written Instructions Not on the Approved List Are Procedures Subject to the USQ } \\
\text { Process (23). }\end{array}$ \\
\hline USQ Asst Prep for CDNS & UD.1-1 Changes Covered by Application of a Categorical Exclusion Required a USQD (31) \\
\hline USQ Asst Prep for CDNS & UD.1-2 CatXs Improperly Documented (32) \\
\hline USQ Asst Prep for CDNS & $\begin{array}{l}\text { UD.1-3 Inadequate Technical Basis (pg 32). Inadequate technical basis for 2002 USQ Screen, } \\
\text { B332-02-027-S, evaluating anchor calculation. USQD should be done on either a procedure } \\
\text { or a physical change, not a calculation. }\end{array}$ \\
\hline
\end{tabular}


As part of the process to verify appropriate reporting to the DOE NTS, and because $90 \%$ of the USQ-related deficiencies identified by the performance analysis were from the one assessment, PARS conducted a more detailed examination of deficiencies for programmatic or systemic noncompliances.

Although the USQ-related deficiencies covered a wide range of specific USQ topics, PARS analysis of the results did reveal one potential systemic noncompliance. Three of the nine USQrelated deficiencies identified in the 2009 USQ Assessment Report specifically addressed compliance with the requirements that all procedures subject to the USQ process be identified and that these procedures (or changes in these procedures) be submitted to the USQ process prior to use.

The assessment objective "Temporary or permanent procedural changes for the facility enter the USQ process as required by ES\&H Manual Document 51.3" (labeled as USQ Process Entry Condition UEC.2 in the assessment report) was the only one in the 2009 USQ Assessment that did not meet the assessment criteria, namely that:

1. An approved list of procedures/procedure types subject to the USQ process exists for each nuclear facility.

2. All written instructions that would constitute procedures per the USQ process are included on the facility list of procedures/ procedure types.

3. Document Control Processes establish that all procedure changes enter the USQ process.

4. Changes to Facility Preventive Maintenance (PM) Task Codes are submitted to the USQ process.

The assessment generally concluded for UEC.2 that:

- "Temporary or permanent procedural changes for facilities do enter the USQ process as required by ES\&H Manual Document 51.3 ... However, [the USQ assessment] review had also identified misunderstandings of what constitutes a procedure under the USQ process."

- "Superblock facilities do not meet review criteria 2 and 3.... RHWM facilities may not meet Criteria 2 and 3, either."

- Contrary to Criterion 4 above, "NNSA/LSO Effectiveness Review of OA-40 Finding \#24 (ISS-TS-2/15/2008-31433) identified select examples of a type of procedure (PM [Preventive Maintenance] Task Codes) that had not been submitted to the USQ process. Subsequent evaluation indicated the problem was more systematic in nature. Additional PM task codes that had not been submitted to the USQ process were identified in multiple facilities."

More specifically, the assessment report noted in deficiency UEC.2-1, that "The review Team identified a Deficiency relating to the document control processes ensuring that all procedure changes enter the USQ process." In deficiency UEC.2-2 (listed in Table 4), "Written Instructions Not on the Approved List Are Procedures Subject to the USQ Process," the assessment report: 
- listed (in Appendix D) 65 procedures explicitly identified by Nuclear Materials Technology Program (NMTP) management as not being subject to the USQ process. The Review Team concluded that at least some excluded procedures met the definition of a "procedure" subject to the USQ process.

- noted that the Review Team identified several NMTP procedures that NMTP had not explicitly excluded from the USQ process, but that in the opinion of the Review Team should have been at least considered for USQ review.

Deficiency UEC.2-2 was further supported by weakness UEC.2-3, "Written Instructions that Constitute Procedures Not Submitted to the USQ process," which identified "misunderstandings of what constitutes a procedure under the USQ process" by questioning the exclusion from the USQ process of Radioactive and Hazardous Waste Management (RHWM) Waste Processing Plans. The assessment report noted that these plans, as described by RHWM, appear to meet the definition of "procedures" that should be entered into the USQ process.

Deficiencies UEC.2-1 and UEC.2-2 were also supported by Deficiency FSCM.1-1, "Facility specific USQ Procedures Contain Instructions in Conflict with the Provisions of ES\&H Manual Document 51.3," which concluded that the procedure describing the NMTP USQ process did not adequately satisfy the requirements in ES\&H Manual Document 51.3 that "The Facility Manager ... maintain a list of facility procedures or procedure types subject to the USQ process" and that "This list of facility procedures or procedure types shall be concurred with by the Safety Basis Division Leader, or designee."

The assessment report also cited several specific sources (e.g., LSO Monthly Assessment Reports, prior NNSA-LSO assessments, the 2008 CDNS Biennial Review of Site Nuclear Safety Performance) as evidence of the repetitive nature of this issue. Deficiency UEC.2-2 is specifically similar to a deficiency included by NNSA-LSO in its June 2008 MAR concerning lack of USQ review of field changes in NMTP procedures. The MAR deficiency was reported to the DOE NTS as a noncompliance. This analysis, however, determined that the USQ assessment identified a programmatic weakness associated with USQ review of procedures that is also reportable to the Noncompliance Tracking System. One aspect of this newly identified noncompliance is the discrepancy between the NMTP USQ process and the institutional USQ procedure that inappropriately allowed field changes to be made without USQ review and that was reported to the NTS. This noncompliance is much broader having to do with the overall process for reviewing procedures. Had PARS first identified and reported to NTS the programmatic noncompliances identified by the USQ assessment, the "field change" discrepancy would have been considered additional evidence of the same issue. However, the fact that the "field change" noncompliance was reported first does not change the fact that the broader programmatic issue identified by the assessment is also NTS-reportable.

As the assessment report explicitly stated in Deficiency UEC.2-2, "In summary, LLNL has not demonstrated the capability to verify that all procedures subject to the USQ process are identified." The apparent systemic weakness, combined with evidence that the problem is repetitive, suggests that a report to the DOE Noncompliance Tracking System is warranted. 


\section{Nuclear Operations-Criticality Safety}

In a previous performance analysis report, criticality safety deficiencies were analyzed using control charts. Based on the nuclear safety Regulatory Compliance Assurance coordinators previous review of criticality safety deficiencies, it was determined that 13 of the 15 criticality safety deficiencies categorized as posting and labeling deficiencies were not related to criticality safety, and should be re-categorized under a different functional area and/or topic. These same deficiencies were reviewed during this quarterly analysis and it was found that of the original 15 posting and labeling criticality safety deficiencies, only two have since been re-categorized under a different functional area. Some of the more interesting deficiencies still categorized as criticality safety include deficiencies with descriptions, cream cheese sitting out for too long, the toaster oven is located on top of a microwave and needs to be seismically secured, the check hands and shoes sign is not posted on inside of lab and exit sign in not visible from the hallway. All deficiencies categorized as posting and labeling criticality safety deficiencies from the third quarter in 2007 are listed in Table 5. These deficiencies need to be revised by the appropriate screeners and/or Operational Review Boards (ORBs) and re-categorized as applicable.

Table 5. Deficiencies Categorized as Posting and Labeling Criticality Deficiencies

\begin{tabular}{|c|c|c|c|}
\hline PD & Owning Org & Issue Title & ITS ID \\
\hline \multicolumn{4}{|l|}{$O \& B$} \\
\hline & PFS & Cream cheese sitting out for too long & 19415.5 \\
\hline & PFS & Exit sign is not visible from the hallway. & 21929.11 \\
\hline \multicolumn{4}{|c|}{ 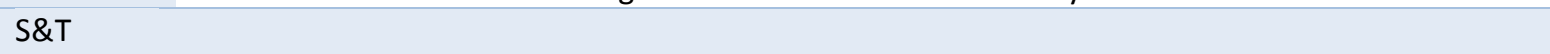 } \\
\hline & ENG & No Chemtrack label & 17991.2 \\
\hline & ENG & No label on bottle & 17991.3 \\
\hline & ENG & Toaster oven not seismically secured & 17991.4 \\
\hline & ENG & Bottle mislabeled & 17991.5 \\
\hline & ENG & Cabinets not labeled with RI contact info & 18211.1 \\
\hline & CME\&LS & Hazardous Waste & 21552.1 \\
\hline & NSED & B141 bay 3 observation & 24071.2 \\
\hline & CME\&LS & Safety signs not posted & 24261.5 \\
\hline \multirow[t]{3}{*}{$\mathrm{WCl}$} & $\mathrm{WCl}$ & criticality safety infraction & 19783.5 \\
\hline & $\mathrm{WCl}$ & criticality safety infraction & 21886.1 \\
\hline & $\mathrm{WCl}$ & radiological postings in B239 & 23118.1 \\
\hline
\end{tabular}


Quality Assurance (Nuclear Safety) Functional Area

As discussed in the previous performance analysis report, a complete set of new quality assurance (QA) compliance codes were added to ITS in June 2008. Due to this addition, a number of general compliance codes were deleted and deficiencies identified with those codes were mapped to the new QA codes.

During this quarter, 39 assessments were performed with issues categorized in the QA functional area. However, only one issue was categorized as related to nuclear safety, as shown in Frequency chart 11. Since 2005, there have been 2,922 deficiencies categorized as QA, with 251 $(9 \%)$ related to nuclear safety based on the nuclear safety screening questions in ITS.

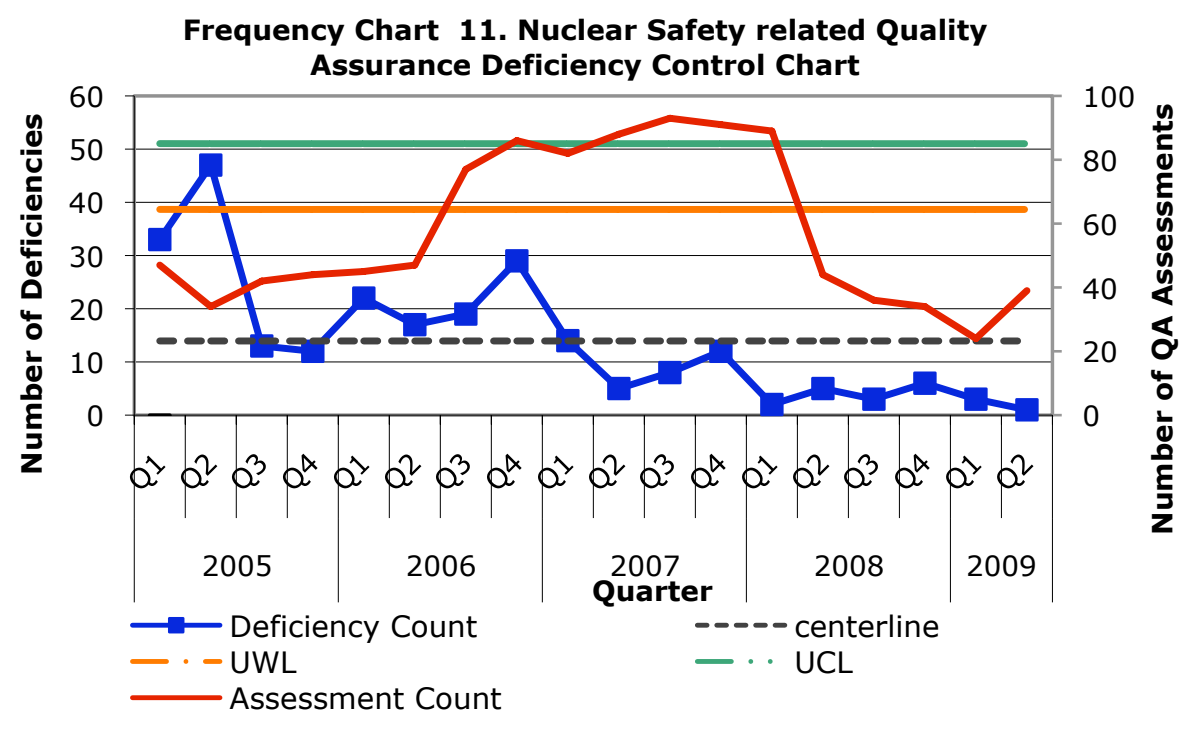

In Frequency chart 11, there appears to be a decreasing trend in nuclear safety related QA deficiencies from the first quarter in 2005 to the second quarter in 2009. This decreasing trend was found to be statistically significant ( $p$-value $<0.01$ ). Based on the results of simple linear regression, with every increase in time (quarter), on average the number of nuclear safety related QA deficiencies decreases by two. The majority of nuclear safety related QA deficiencies since 2005 fall within two criterion, $48 \%$ in criterion four (Management/Documents and Records) and 23\% in criterion two (Management/Personnel Training and Qualification).

The decreasing trend in nuclear safety related QA deficiencies can be attributed to the introduction of more binning options for nuclear safety noncompliances. Additional functional areas were introduced in October 2008, and additional safety basis compliance codes were introduced in January 2008. Also, since ITS allows the selection of only one compliance code for each deficiency, the Performance, Analysis and Reporting Section (PARS) of the Contractor Assurance Office encourages users to select the appropriate safety area (or best-fit compliance code) first when binning deficiencies. For example, if a nuclear safety deficiencies would better fit in the radiation protection functional area compared to the QA functional area, because the radiation protection functional area offers more specifics related to the noncompliant condition, then PARS would prefer it be categorized as radiation protection and not QA. Therefore. it is not surprising that the number of nuclear safety related deficiencies have decreased over time. 
However, this functional area will be added to the watch list to see if the decreasing trend is still apparent in future analyses, but at this time is not identified as reportable to the DOE NTS.

\section{Reportable to NTS}

Quality Assurance (all types) Functional Area

All QA deficiencies were also examined to see if there is a decreasing trend in the overall number of these deficiencies over time, not just the nuclear safety-related QA deficiencies. There does not observationally appear to be a decreasing trend in QA deficiencies over all quarters, although there does appear to be a recent decreasing trend since the fourth quarter in 2007, as shown in Frequency chart 12. Using linear regression, there was no statistically significant trend related to all QA deficiencies.

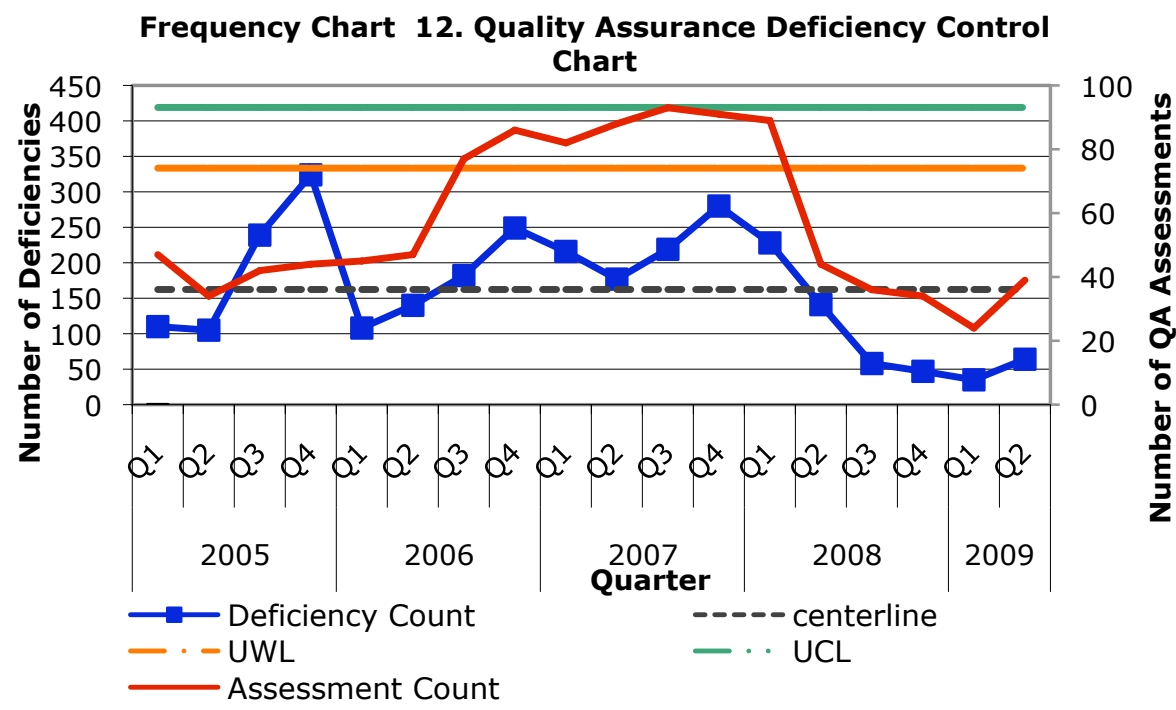




\section{Radiation Protection Functional Area}

During this quarter the radiation protection related deficiencies increased to eight from two in the first quarter of 2009 to eight in the second quarter of 2009, as shown in Frequency chart 13. These eight deficiencies were categorized as five different subtopics, design and control $(n=2)$, posting and labeling $(\mathrm{n}=2)$, radiation protection records $(\mathrm{n}=2)$, monitoring of individuals areas $(\mathrm{n}=1)$ and radioactive contamination control $(\mathrm{n}=1)$. Radiation protection deficiencies have been decreasing since the third quarter in 2007 with a small increase in this quarter. Since a common test was met, an increase in deficiencies for the most recent quarter, this functional area will be placed on the watch list. The deficiencies are that the calibration program for the tritium monitors does not meet requirements; that deficiencies from the prior 10 CFR 830.102 assessment were not entered into ITS; four were related to inadequacy of documents and records, including procedures; the eighth was for not performing a semi-annual radiation generating device (RGD) survey. At this time, the collection of deficiencies do not constitute a significant or a systemic or programmatic noncompliance reportable to the DOE NTS.

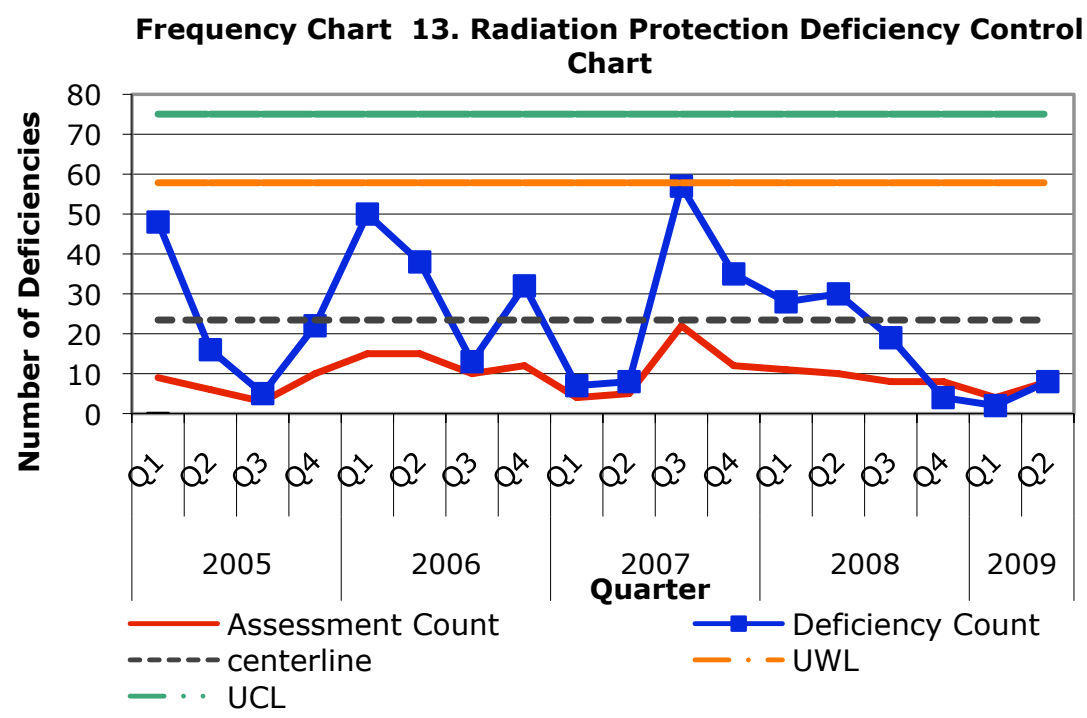


Radiation Protection-Design and Control

During this quarter, there were eight assessments performed with issues categorized in the radiation protection functional area. These eight assessments found two RP-design and control deficiencies, as shown in Frequency chart 14. These two deficiencies were categorized as, design reviews for new facilities or for facility modifications were not performed as required or did not include ALARA considerations, and physical design features, administrative controls, or work practices are not consistent with ALARA objectives.

Frequency Chart 14. RP-Design and Control Deficiency Chart

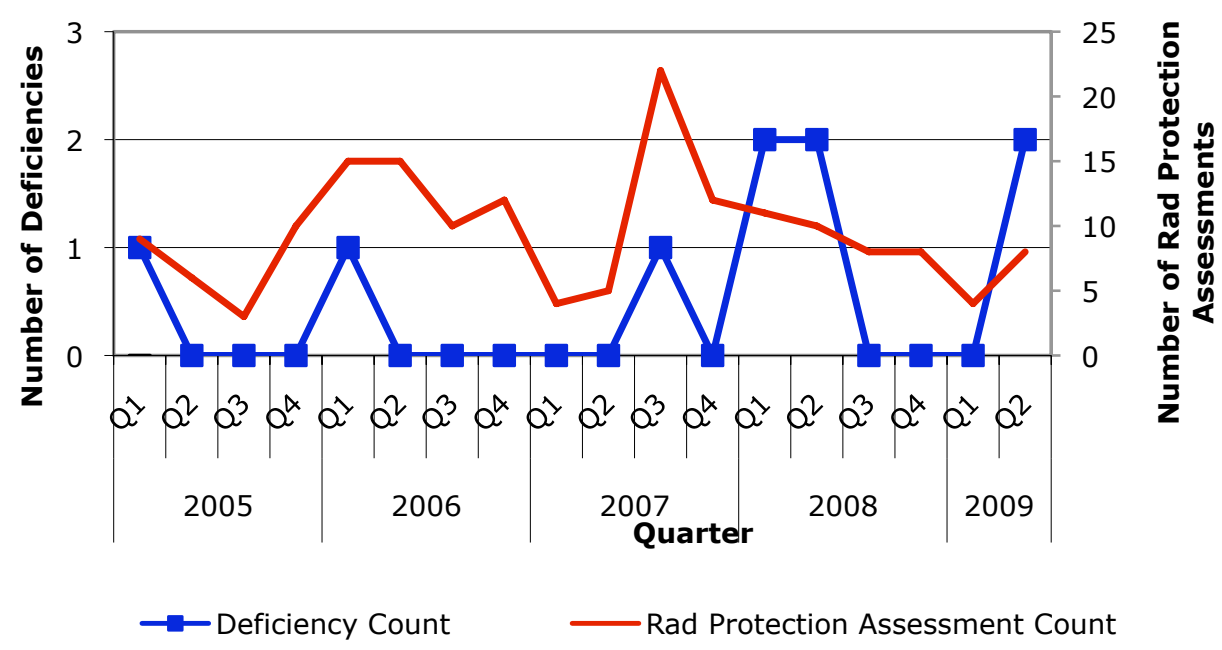

Note that the sample size for this topic is very small, so the control limits and the centerline have not been included on Frequency chart 143, although they were used in the past. Some of the common tests can still be used even without the control limits and centerline. It was found in the previous quarterly analysis that one of the two deficiencies reported in the second quarter of 2008 was incorrectly categorized as a RP-design and control deficiency, which decreases our sample size by one. Since a common test was recently met, an increase in deficiencies for the most recent quarter, this subtopic will remain on the watch list, but at this time is not identified as reportable to the DOE NTS. 
Radiation Protection-Posting/Labeling During this quarter there were eight assessments performed with issues categorized in the radiation protection functional area. From these assessments, two RP-posting/labeling issues were found, as shown in Frequency chart 15. These two deficiencies were categorized as, required radiological signs are not clearly and conspicuously posted and not otherwise specified; description of deficiency required. This last deficiencies was titled, "HP Technician found RGD label incorrectly placed."

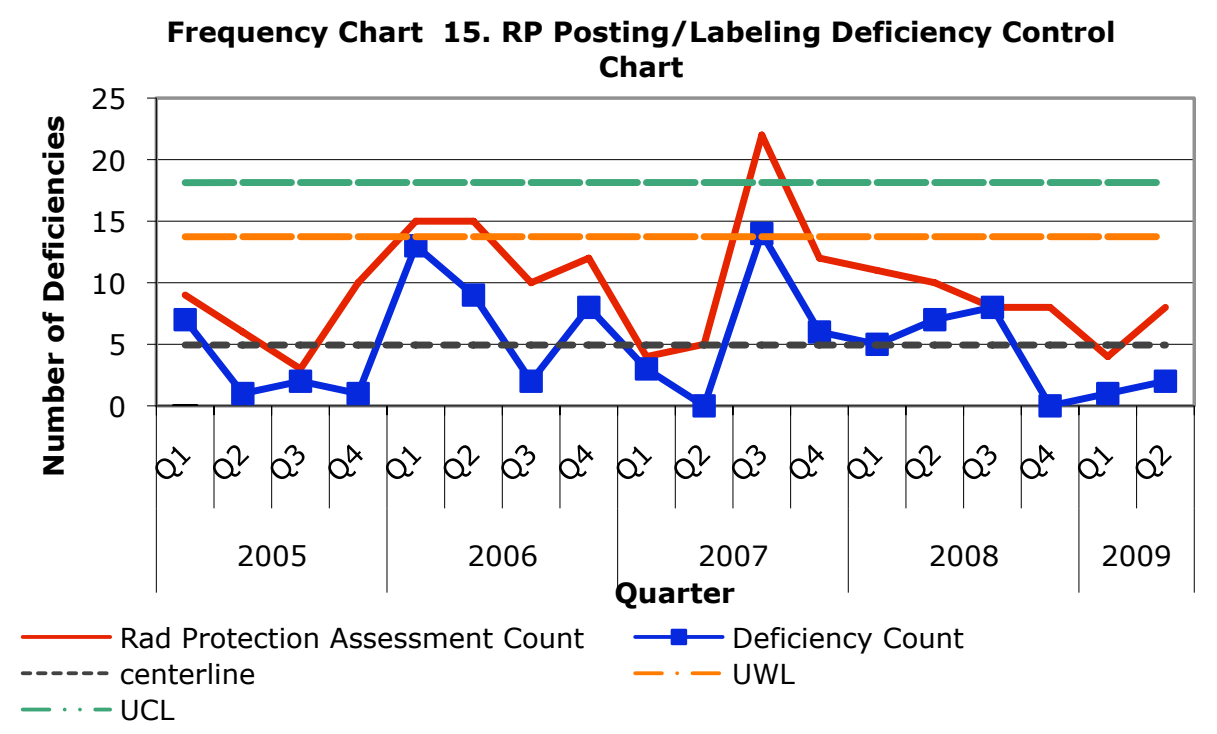

There was an increase in these type of in the fourth quarter in $2008(n=0)$ to the second quarter in $2009(n=2)$. Since a common test was recently met, two consecutive increases in the number of deficiencies over at least two quarters, this subtopic will remain on the watch list, but at this time, the deficiencies are not identified as reportable to the DOE NTS.

Reportable to NTS

$\square$ Not reportable to NTS

$\triangle$ Watch List 


\section{3 "Other Significant Condition" Noncompliances}

\section{Method}

The WSH "Other Significant Condition" NTS reporting threshold is defined as, "a condition or hazard that has the potential to cause death or serious physical harm (injury or illness). "This would include, at a minimum, significant noncompliances with high relative risk, as defined in ES\&H Manual Document 4.4. These deficiencies are identified in ITS, at a minimum as having an issue significance of one. There were two methods used to review ITS data for deficiencies that may meet the "Other Significant Condition" NTS reporting threshold:

1. A review of all issue significance one deficiencies with notification dates starting in January through December 2008.

2. Review of all deficiencies with compliance codes that suggest an issue significance of one, but were downgraded, to confirm that the downgrade was supported.

In order to confirm that an issue significance downgrade was supported, Figure 1, the Risk Matrix and Table 1, the Severity of Issue Guide were used from PRO-0042-00, "Issues and Corrective Action Management." For an issue to be assigned a significance of a one, the severity of consequence would have to be either "High" or "Catastrophic" and the probability "Likely" or "Frequent." If an issue has a severity of consequence of "Medium", "Low" or "Negligible" and the probably is "Unlikely" or "Extremely Unlikely," then the issue significance would be a two or lower, and the issue would not meet the WSH "Other Significant Condition" NTS reporting threshold.

\section{Results}

There was one deficiency with an issue significance of one entered into ITS as of the date the data was pulled for this analysis. However, as of September 22, 2009, the issue significance was downgraded to an issue significance three. The issue was described as a WSH deficiency titled, "Damaged cord on energized battery charger." Based on this description this deficiency was appropriately downgraded from an issue significance one to a three. Therefore, this deficiency does not meet the NTS reporting threshold for WSH as an "Other Significant Condition" noncompliance and is not reportable to the DOE NTS.

There were 16 deficiencies assigned a compliance code with a suggested issue significance of one in 2009, but downgraded to another issue significance, see Table 6. 


\section{Table 6. Deficiencies Downgraded from an Issue Significance One in 2008}

\begin{tabular}{|c|c|c|c|}
\hline Seq & $\begin{array}{l}\text { Issue } \\
\text { Sig }\end{array}$ & $\begin{array}{l}\text { Issue } \\
\text { Sub-Topic }\end{array}$ & Deficiency Description \\
\hline 1 & 2 & Carcinogens & 60-40 lead solder on floor in R1600.Collect/dispose as directed by EA \\
\hline 2 & 3 & $\begin{array}{l}\text { Evacuation } \\
\text { of } \\
\text { Occupants }\end{array}$ & $\begin{array}{l}\text { Fire door D150 was left open [fixed by closing the door, however, the door will not } \\
\text { close automatically; per a sign posted on the door it needs to be physically closed as } \\
\text { an impairment control] }\end{array}$ \\
\hline 3 & 2 & $\begin{array}{l}\text { Evacuation } \\
\text { of } \\
\text { Occupants }\end{array}$ & $\begin{array}{l}\text { The hardware should be replaced as soon as you are able to make it happen. I } \\
\text { would classify it as a } 2 \text { in the ITS system. As currently arranged it can take two } \\
\text { actions to exit from this main door. The life safety code says that doors are to only } \\
\text { require one action to open the door. }\end{array}$ \\
\hline 4 & 3 & $\begin{array}{l}\text { General } \\
\text { Electrical }\end{array}$ & Electrical outlet cover missing in T5627, R1011 \\
\hline 5 & 3 & $\begin{array}{l}\text { General } \\
\text { Electrical }\end{array}$ & $\begin{array}{l}\text { Stainless steel table top holding electronic analysis equipment should be grounded. } \\
\text { R1729, characterization lab. }\end{array}$ \\
\hline 6 & 3 & $\begin{array}{l}\text { General } \\
\text { Industrial } \\
\text { Safety }\end{array}$ & $\begin{array}{l}\text { During the pouring of LN2 from a laboratory dewar an employee did not wear their } \\
\text { secondary protection, faceshield. The Employee was wearing safety glasses with } \\
\text { sideshields, appropriate clothing attire, and gloves during procedure. }\end{array}$ \\
\hline 7 & 3 & $\begin{array}{l}\text { General } \\
\text { Industrial } \\
\text { Safety }\end{array}$ & $\begin{array}{l}\text { Proper personal protective equipment (PPE) was not in place on April } 23,2009 \text {, prior } \\
\text { to the cutting of empty electrical conduit located directly above power panels in } \\
\text { Building } 691 \text {, Room } 116 \text {. Although the conduits actually cut were themselves empty, } \\
\text { the adjacent power panels were energized, making this a work activity near } \\
\text { energized electrical equipment. The lack of PPE constitutes a noncompliance with } \\
\text { the requirements of the Occupational Safety and Health Administration, specifically } \\
29 \text { CFR } 1910.335 \text {. }\end{array}$ \\
\hline 8 & 3 & $\begin{array}{l}\text { Ladders/ } \\
\text { Scaffolding }\end{array}$ & $\begin{array}{l}\text { The FIB RI has a step ladder behind the FIB that he periodically uses to fill a } \\
\text { detector high on the microscope with liquid nitrogen. He has tubing draped across } \\
\text { the lower step of this step ladder and there is concern over a tripping hazard. There } \\
\text { are space constraints, which do not make for an obvious solution to the issue. }\end{array}$ \\
\hline 9 & 2 & $\begin{array}{l}\text { Ladders/ } \\
\text { Scaffolding }\end{array}$ & Issue 1: 8-foot wooden ladder has loose rubber feet. \\
\hline 10 & 3 & $\begin{array}{l}\text { Ladders/ } \\
\text { Scaffolding }\end{array}$ & Ladder, near elevator \#2, tied off to conduit [fixed] \\
\hline 11 & 2 & Laser & $\begin{array}{l}\text { The second noncompliance relates to laser operations and addresses inadequate } \\
\text { safety interlocks. The ANSI standard Z136.1 requires that interlock systems are } \\
\text { designed to immediately deactivate the laser. In this case, the interlock system in the } \\
\text { Callisto Target Bay activated a pneumatic shutter on the laser beam tube which } \\
\text { does not fully deploy in a timely manner. }\end{array}$ \\
\hline 12 & 3 & Laser & Interlock reset not functioning. \\
\hline 13 & 3 & Laser & $\begin{array}{l}\text { Per B. Conaway statements: Ensure the interlock by-pass time duration meets } \\
\text { standards. }\end{array}$ \\
\hline 14 & 2 & $\begin{array}{l}\text { Lockout/ } \\
\text { Tagout }\end{array}$ & $\begin{array}{l}\text { Proper lockout/tagout (LOTO) was not in place on April } 23,2009 \text {, prior to the cutting } \\
\text { of empty electrical conduit located directly above power panels in Building } 691 \text {, } \\
\text { Room } 116 \text {. Although the conduits actually cut were themselves empty, the adjacent } \\
\text { power panels were energized, making this a work activity near energized electrical } \\
\text { equipment. The lack of LOTO constitutes a noncompliance with the requirements of } \\
\text { the Occupational Safety and Health Administration, specifically } 29 \text { CFR } 1910.147 \text {. }\end{array}$ \\
\hline 15 & 3 & $\begin{array}{l}\text { Lockout/ } \\
\text { Tagout }\end{array}$ & $\begin{array}{l}\text { Electrical Loto improperly used. Tags are out of date and are not complete. B622, } \\
\text { Room } 101 \text { northwall electrical panel. }\end{array}$ \\
\hline 16 & 3 & $\begin{array}{l}\text { Machinery } \\
\text { and Power } \\
\text { Tools }\end{array}$ & $\begin{array}{l}\text { four blue colored chill water pumps with sections of rotating shafting not fully } \\
\text { guarded in } \mathrm{Rm} 2440 \text { mechanical room. }\end{array}$ \\
\hline
\end{tabular}


Three of the 16 deficiencies from Table 6, sequences 7, 11 and 14 were noncompliances that were already reported to the DOE NTS, with two of the noncompliances reported in the same report:

1. “Near Miss Involving Non-authorized Energized Work in Building 691," [NTS-LSOLLNL-LLNL-2009-0008]

1. “Building 174 Laser Operations Procedural Weakness," [NTS-LSO-LLNL-LLNL-20090002]

2. “Near Miss Involving Non-authorized Energized Work in Building 691," [NTS-LSOLLNL-LLNL-2009-0008]

Based on a review of deficiency descriptions for sequence 1-4, 6, 8-10 and 15 from Table 6, none of these deficiencies should have been given an issue significance of one. Therefore these issues were properly downgraded from an issue significance one and do not meet the DOE reporting threshold for WSH.

The electrical Subject Matter Expert (SME) provided guidance for the electrical related deficiency, (sequence 5 in Table 6). The severity of consequence of a worker receiving a shock related to this deficiency, assuming there was a short in the equipment could be "High" or "Catastrophic." However the probability that either severity of consequence associated with the noncompliance could reoccur anywhere at the Laboratory is less than "Likely." Therefore this issue was properly downgraded from an issue significance one and does not meet the DOE reporting threshold for WSH.

The laser SME provided guidance for the laser related deficiencies, (sequences 12 and 13 in Table 6). The deficiency from Table 6 titled, "Interlock reset not functioning" was determined to have been properly downgraded from an issue significance one. In this particular case, once a person is past the edge of the table, the hazard no longer exists. The other laser related deficiency is written in the form of an action, and is therefore not a noncompliance. Therefore these laser deficiencies do not meet the DOE reporting threshold for WSH.

The machine guarding SME provided guidance for the machinery and power tool related deficiency (sequence 16 in Table 6). Based on the remote location of the chill water pumps, which are difficult to access, this deficiency was given the probability of less than likely. Therefore this deficiency does not meet the DOE reporting threshold for WSH 


\subsection{Evaluation of Response to Assessment Results}

LLNL reported a total of 16 WSH and nuclear safety noncompliances to the DOE NTS in 2009. Eleven of the 16, $(69 \%)$ noncompliances were self-identified:

1. "Beryllium and Lead Found in Bulk Samples From Building 298 Yard Bead Blaster Unit"

2. "Building 298 Yard Bead Blaster Unit Footprint Contamination"

3. "Unexpected Beryllium Contamination Found in Building 298 Beryllium Work Area"

4. "Near Miss Involving Non-authorized Energized Work in Building 691"

5. "Near Miss: Retention Tank Roof Access Without Fall Protection"

6. "Potential Inadequacy in the B331 Safety Analysis - Material at Risk in the Superblock Yard"

7. "Near Miss - Non-energized electrical cable cut without proper isolation"

8. "Inadequacy in the B334 Safety Analysis Regarding Fire Analysis"

9. “B239 TSR Violation"

10. "Safety Basis Violation relative to the Mobile Weapons Platforms in the Superblock Yard"

11. "Programmatic Noncompliances related to the Implementation of LLNL Electrical Safety Program"

The five other noncompliances reported to the DOE NTS in 2009 were identified by an external organization or by events:

1. "Mechanical Lock Failure on Door to Main Electrical Transformer in Building 191"

2. "Rapid Pressure Pulse During Treatment Activities Leads to Loss of Radioactive Material"

3. "Building 174 Laser Operations Procedural Weakness"

4. "Unauthorized Work on Lighting Switch in Building 453 Office"

5. "Repetitive Facilities and Infrastructure Work Control Noncompliance" 
For this quarter, $89 \%$ of the noncompliances reported to the DOE NTS were self-identified. This is the highest percent self-identified in any quarter, as shown in Figure 11.

Figure 11. Discovery Method for Noncompliances Reported to NTS

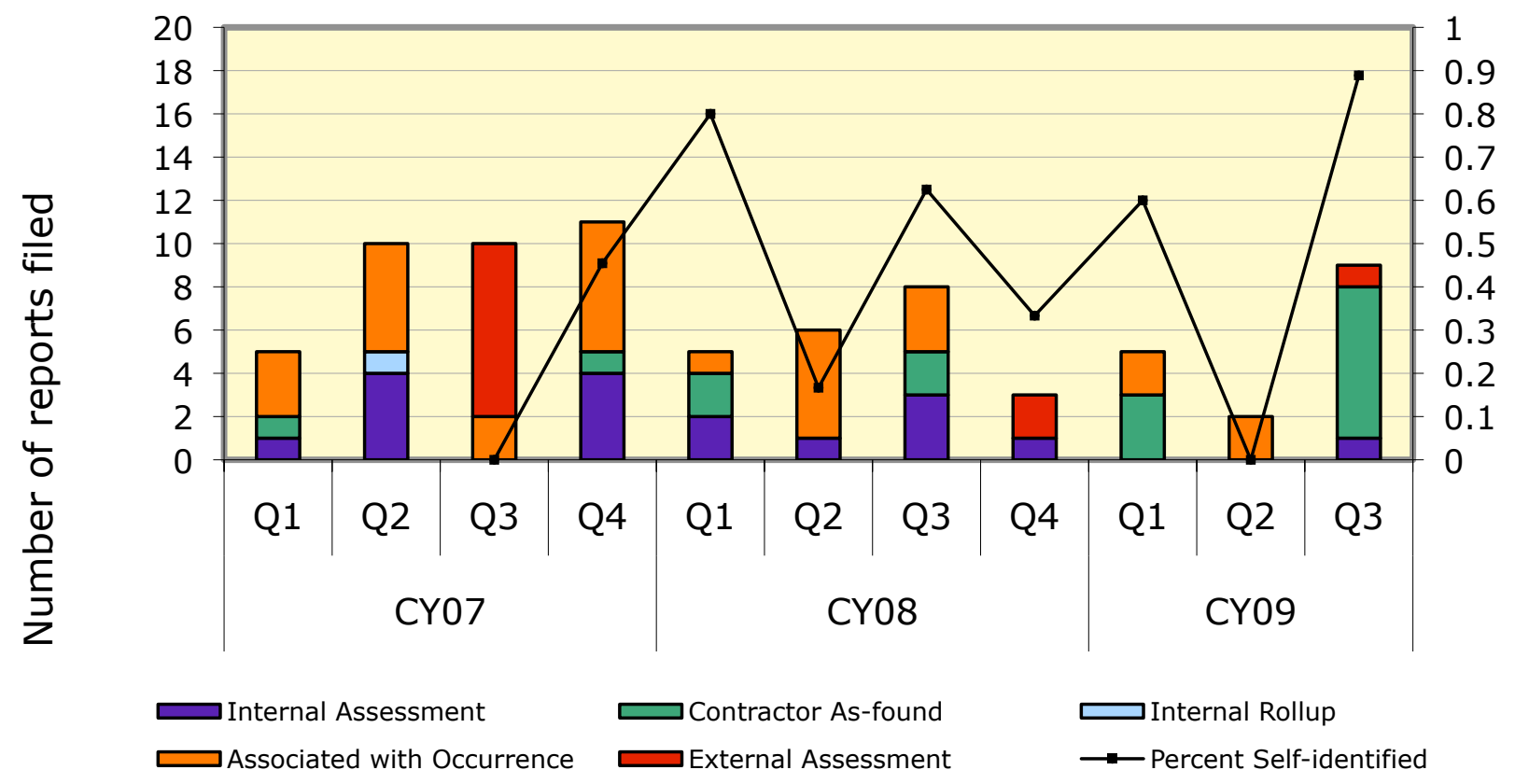

One possible explanation for this increase is a change in the way noncompliances associated with occurrences are determined to be "self-identified." In mid-2007, when WSH enforcement began, through most of 2008, any WSH noncompliance associated with an occurrence was considered discovered "By an Event." In late- 2008, WSH noncompliances related to management concern occurrences and near miss occurrences have been evaluated as to the discovery method and may have been reported as self-identified. As of August 2009, noncompliances associated with all types of occurrences are evaluated for discovery method based on feedback provided from directorates and internal discussions. Also, as of August 2009, the Regulatory Compliance Assurance Section of the Contractor Assurance Office has used the criteria that a true event happened, a shock, occupational injury, exposure above thresholds, explosion or fire etc., for a noncompliance to be discovered "By an Event." 
There were six noncompliances reported in 2009 that took over 200 days to report, as shown in Figure 12. These were identified in July, October, and November 2008 and in January 2009. Four of the six were nuclear safety as found noncompliances related to occurrences. Two were WSH noncompliances; one was a repetitive noncompliance identified by the LSO Monthly Assessment Report in October 2008 and the other was related to an occurrence, the retention tank roof access without fall protection.

Figure 12. Timeliness of Reporting Noncompliances to the NTS

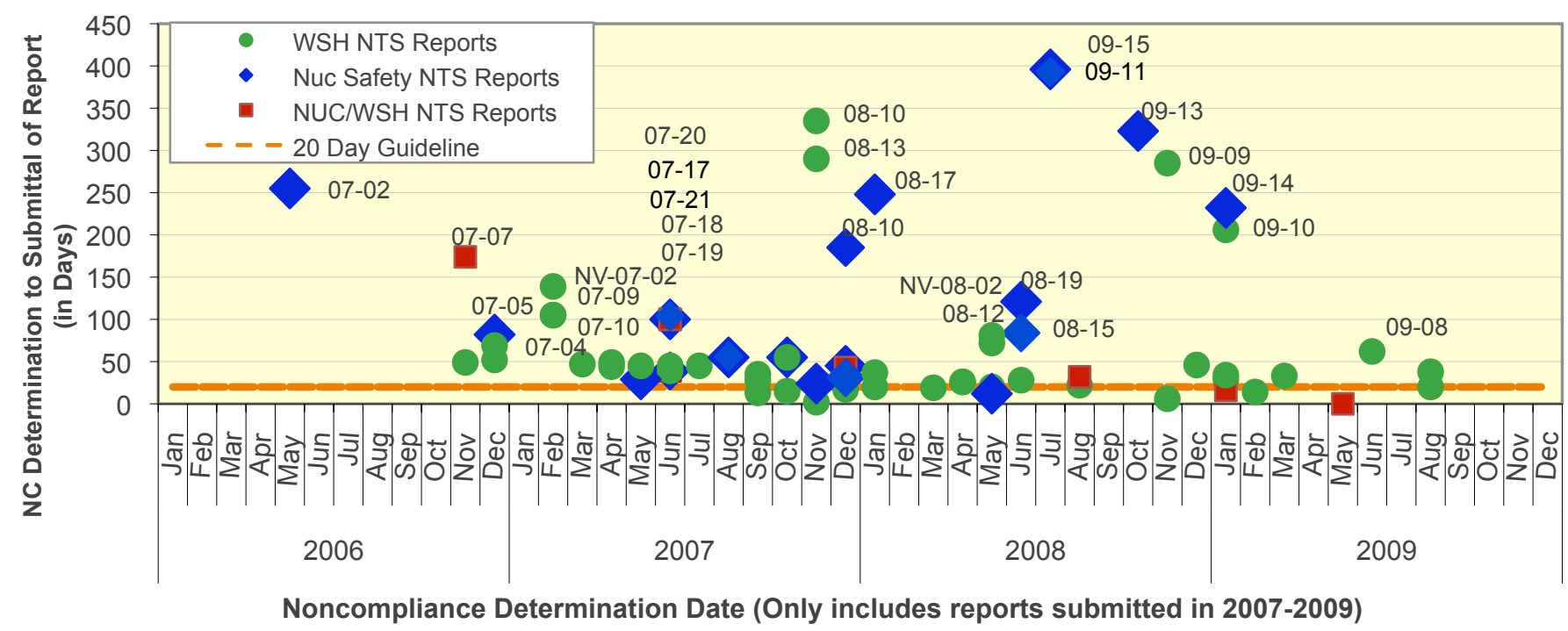

When the average number of days to report a noncompliance to the DOE NTS is calculated for each year based on the year the noncompliance was determine, which is how Figure 12 is displayed, the average number of days for 2009 is 62 days, which is less than 2008 when it was 109 days. This is due to a back log of noncompliances determined to be either a WSH or nuclear safety noncompliance in 2008, but the noncompliance was not reported to the DOE NTS until 2009. Although LLNL did not meet the Office of Enforcement's expectation of prompt reporting within 20 days after determining a noncompliance exists, the timeliness of submitting noncompliances to the DOE NTS has improved for those determined to be noncompliances in 2009 and reported in 2009. 
Target completion dates for actions related to NTS reported noncompliances can be extended with justification noted in the NTS system. If an action is responding to an external assessment, the extension must be granted by the assessing organization and the process to request the extension requires a memo from the LLNL Deputy Director to the assessing organization. Table 7 describes the percent of actions completed on-time and extended Lab-wide and also by principle directorate (PD). For all actions, completed as of October 1, 2009, 95\% have been completed on-time. This is more than both 2007 and 2008 where $93 \%$ and $85 \%$ of actions were completed on-time. Four PDs have completed all actions on time so far in 2009, Global Security (GS), NIF and Photon Science (N\&PS), Science and Technology (S\&T) and Weapons and Complex Integration (WCI).

Table 7. Percent of Actions Extended and Completed On-time by Principle Directorate

\begin{tabular}{|c|c|c|c|c|c|c|}
\hline \multirow[t]{2}{*}{ By PD } & \multicolumn{3}{|c|}{$\%$ Extended of all actions due } & \multicolumn{3}{|c|}{$\%$ Completed On-time of actions completed } \\
\hline & CY07 & CY08 & $\begin{array}{c}\text { CY09 } \\
\text { (as of } 10 / 1 / 09)\end{array}$ & CY07 & CY08 & $\begin{array}{c}\text { CY09 } \\
\text { (as of } 10 / 1 / 09)\end{array}$ \\
\hline DO & $21 \%(15 / 70)$ & $6 \%(6 / 94)$ & $18 \%(12 / 68)$ & $95 \%(70 / 74)$ & $88 \%(81 / 92)$ & $92 \%(48 / 52)$ \\
\hline GS & $(0 / 0)$ & $36 \%(5 / 14)$ & $(3 / 2)$ & $(0 / 0)$ & $100 \%(14 / 14)$ & $100 \%(2 / 2)$ \\
\hline N\&PS & $17 \%(4 / 24)$ & $20 \%(2 / 10)$ & $5 \%(2 / 37)$ & $100 \%(23 / 23)$ & $100 \%(10 / 10)$ & $100 \%(23 / 23)$ \\
\hline$O \& B$ & $6 \%(4 / 62)$ & $29 \%(16 / 56)$ & $55 \%(21 / 38)$ & $90 \%(55 / 61)$ & $58 \%(33 / 57)$ & $85 \%(29 / 34)$ \\
\hline S\&T & $29 \%(2 / 7)$ & $10 \%(1 / 10)$ & $4 \%(1 / 28)$ & $100 \%(9 / 9)$ & $100 \%(8 / 8)$ & $100 \%(25 / 25)$ \\
\hline WCI & $28 \%(20 / 71)$ & $3 \%(4 / 121)$ & $50 \%(36 / 72)$ & $92 \%(81 / 88)$ & $92 \%(97 / 106)$ & $100 \%(39 / 39)$ \\
\hline Lab-Wide & $19 \%$ & $11 \%$ & $31 \%$ & 93\% & $85 \%$ & $95 \%$ \\
\hline
\end{tabular}

There has been an increase in the percent extended when comparing 2007 (19\%) and $2008(11 \%)$ to CY09 (31\%). Four PDs had an increase in their percent extended so far in 2009 compared to 2008, DO, GS, O\&B and WCI. GS extended one of the two actions due in CY09 three times, the reason the percent extended is greater than $100 \%$. 


\subsection{Other Functional Areas}

\section{Environment}

There are 1,077 issues categorized in the functional area environment since 2005. There was an increase in environment issues from 2008 to 2009. In 2009, LSO performed an Environment Management System Audit and identified 98 issues, all owned by ESH\&Q with no topic or subtopic identified. Eighty nine of these were categorized as observations.

Eighty four percent $(84 \%)$ of all environment issues are deficiencies with $83 \%$ related to waste and water quality. There is an increase in the number of environment deficiencies in 2007, as shown in Figure 13. Twenty percent $(20 \%)$ are deficiencies from the due diligence walkdowns completed prior to transition. Since 2007, the number of environmental deficiencies has decreased.

Figure 13. Environment Issues/Deficiencies by Topic and Year

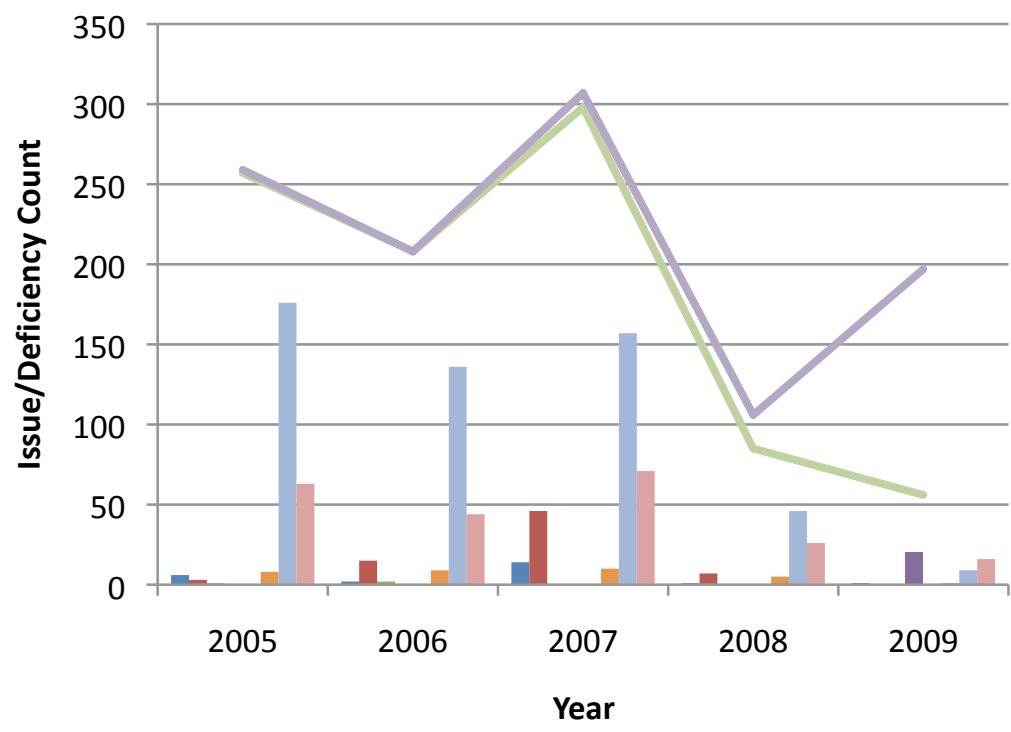

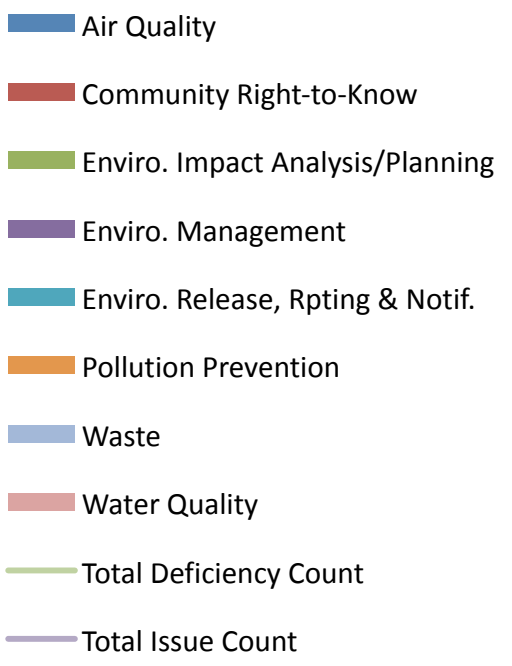




\section{Facility Management}

Ninety one facility management issues have been entered into ITS since 2005 and 34 of these issues were categorized into subtopics, as shown in Figure 14. The majority of these issues, 95\% are observations. Only one of the five deficiencies has a topic and subtopic, categorized as surveillance and maintenance requirements. The majority, $79 \%$ of the facility management issues were identified in 2008, with 17\% from one assessment titled, "2008 CMELS Confined Space Self Assessment."

Figure 14. Facility Management Issues by Subtopic and Year

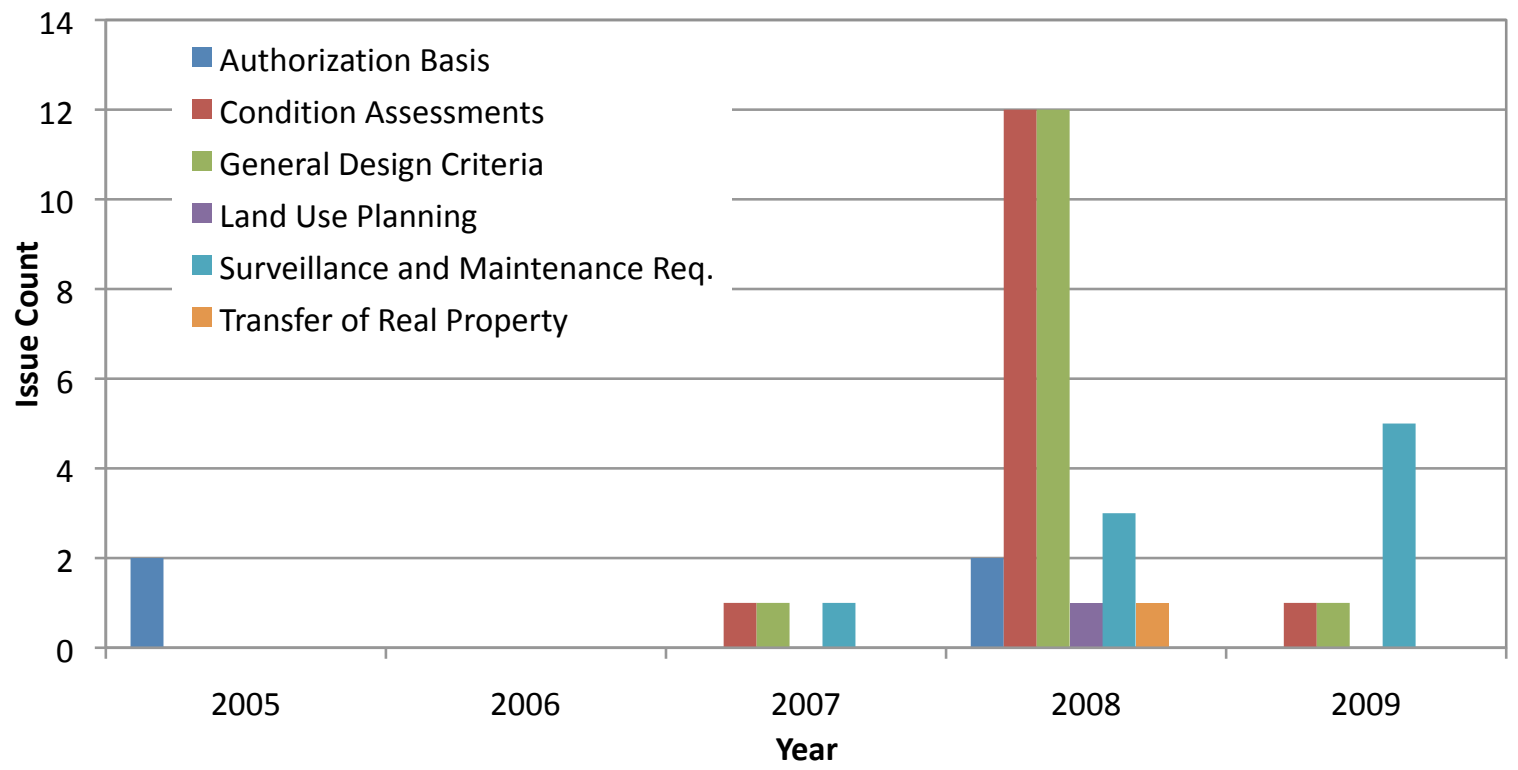




\section{Transportation}

There are a total of 57 transportation issues in ITS since 2005. The majority of transportation issues were entered in 2008 with 59\% of these from NIF Management Self Assessments. Seventy four percent $(74 \%)$ of transportation issues are observations; 30 issues had topics with the majority in the training and qualifications requirement $(47 \%)$ and training and qualifications program (37\%) topics, as shown in Figure 15.

Figure 15. Transportation Issues by Topic and Year
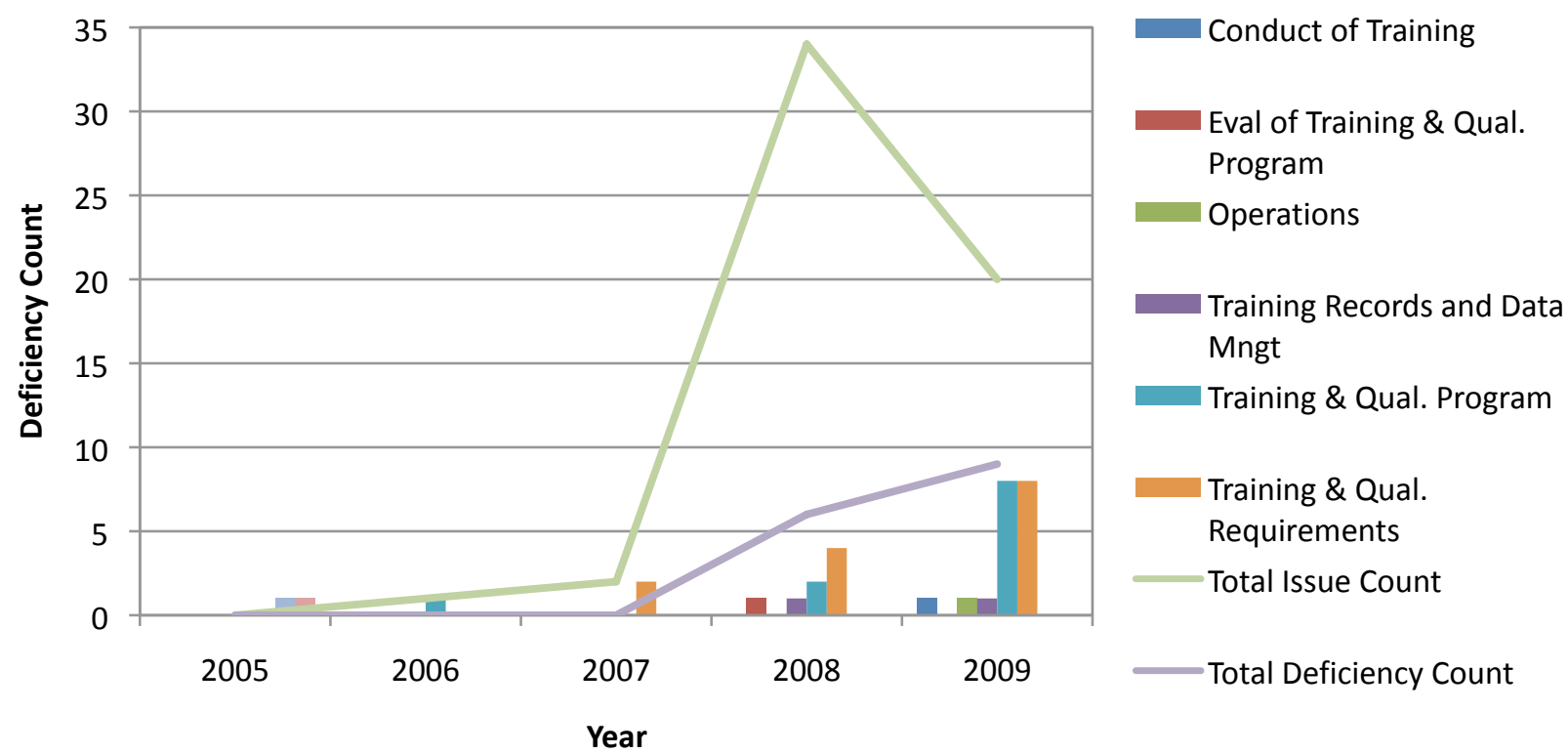


\subsection{Conclusion}

Analysis of the issues lead us to conclude that LLNL is entering fewer items into the ITS and conducting fewer assessments than in previous years. The analysis identified two systemic/ programmatic noncompliances that appear to meet the requirements for reporting to the DOE NTS. In addition, four subtopics were placed on the watch list for further evaluation in future analyses.

There are a total of 17 assessments results that are pending noncompliance evaluations, with three reports issued prior to 2009. Some of these are pending evaluations because either the assessment was not entered into ITS and an assessment response owner was not assigned or the basic assessment information was entered into ITS, but the corresponding deficiencies and associated corrective actions were not. In several cases, the assessment information had been in ITS for a significant length of time without further action (e.g., causal analysis, corrective actions) having been taken. Specifically two assessments, the Boiler Safety and the 10CFR851 WSH Program for Procured Service Subcontractors are pending assignment of a point of contact so the noncompliance evaluation and potential reportability to the DOE NTS can be completed. Six of the 17 are related to the 10CFR835.102 audits, all issued in 2009.

Recommendation: Complete the evaluation and report the apparent programmatic weakness related to the evaluation and response to findings in completed assessment reports.

So far in 2009, LLNL has site-reported 52\% of deficiencies as WSH noncompliances and $17 \%$ of deficiencies as nuclear safety noncompliances. This is less than 2008 (62\%) for WSH, but more than 2008 (7\%) for nuclear safety. Specifically for WSH, the percentage of site-reportable noncompliances in the second quarter of 2009 is the lowest in the last six quarters.

The control chart analysis did identify one subtopic that appears to have a systemic noncompliance. Safety basis deficiencies identified by a single LLNL management assessment titled, "USQ Assessment Report in Preparation for CDNS Review," were determined to be an apparent systemic noncompliance related to the requirements that all procedures subject to the USQ process be identified and that these procedures (or changes in these procedures) be submitted to the USQ process prior to use.

Recommendation: Complete the evaluation and report the apparent systemic weakness related to the USQ Process Entry Condition. The assessment report explicitly stated in Deficiency UEC.2-2, "In summary, LLNL has not demonstrated the capability to verify that all procedures subject to the USQ process are identified."

The analysis did suggest four related subtopics that should be placed or remain on the watch list. These subtopics will be observed over future quarters for consecutive increases in the number of the deficiencies or points above the control limits:

- Electrical

- Laser 
- Radiation Protection-Design and Control

- Radiation Protection-Posting/Labeling

Recommendation: Include the four subtopics in future performance analysis.

There is a statistically significant decreasing trend in the number of WSH deficiencies entered into ITS. On average, for every increase in time (one quarter) the WSH deficiency count decreased by 35. It was found using a correlation test that the number of WSH deficiencies is decreasing as the number of WSH observations is increasing over time. It was also found that $35 \%$ of sampled WSH observations should have been categorized as deficiencies, with $26 \%$ of issue descriptions not providing enough information to make a determination.

Recommendation: Screeners and ORBs review how issues are labeled, specifically when selecting the Issue Type in ITS. To site report nuclear safety and WSH noncompliances the Issue Type must be DEFICIENCY with the appropriate screening questions marked.

Recommendation: Screeners and ORBs assure enough information is provided about the issue in the issue description so that a determination could be made whether an issue is a deficiency or an observation just by reading the issue description from ITS.

In re-examining criticality safety deficiencies that were previously analyzed and reported to have been incorrectly categorized as criticality safety, it was found that 13 of the 15 criticality safety deficiencies have not since been re-categorized under an appropriate functional area/topic/subtopic. Some of the more interesting deficiencies, still under critically safety topic, are, cream cheese sitting out for too long, the toaster oven is located on top of a microwave and needs to be seismically secured, the check hands and shoes sign is not posted on inside of lab and exit sign in not visible from the hallway.

Recommendation: Screeners or ORBs for OEB, SET and WCI to look at their criticality deficiencies listed in Table 5 in Section 4.2 and re-bin them in more appropriate functional areas, topics and subtopics and compliance codes.

There was one deficiency, assigned an issue significance of one, which met the "Other Significant Condition" NTS reporting threshold at the time the data was pulled. However, the deficiency was re-evaluated and appropriately downgraded to an issue significance three. Therefore, this deficiency is not reportable to the DOE NTS.

The 16 deficiencies entered in ITS in 2009 and downgraded from a suggested issue significance of one, to another issue significance were evaluated. Three of the 16 were reported to the NTS as 
event related. Based on the other 13 deficiencies descriptions, the Risk Matrix and Severity of Issue Guide from PRO-0042-00 and input from the appropriate SME, all 13 deficiencies were considered to be appropriately downgraded from an issue significance one and are considered as site-reportable-only WSH deficiencies.

LLNL reported a total of $16 \mathrm{WSH}$ and nuclear safety noncompliances to the DOE NTS from January 2009 through September 2009 with 11 self-identified. In the July-September 2009 quarter, $89 \%$ of the noncompliances reported to the DOE NTS were self-identified, which is the highest percent self-identified in a quarter to date. On average, it took LLNL 62 days to report the noncompliances to the DOE NTS in 2009. Although this does not meet the Office of Enforcements Expectation of 20 days, it is an improvement compared to 2008 (109 days).

For all NTS reported actions, completed so far in 2009, 95\% of actions have been completed on-time. This is more than 2008 when $85 \%$ of the actions were completed on-time. However there has been an increase in the percent of actions extended when comparing $2008(11 \%)$ to $2009(31 \%)$, which may account for less actions completed late in 2009. 


\subsection{Definitions}

Correlation: The strength of the linear relation between two quantitative variables (e.g. observations and deficiencies).

Correlation Coefficient (Rho): A number between -1 and 1 which measures the degree to which two variables are linearly related. If there is perfect linear relationship with positive slope between the two variables, we have a correlation coefficient of 1 ; if there is positive correlation, whenever one variable has a high (low) value, so does the other. If there is a perfect linear relationship with negative slope between the two variables, we have a correlation coefficient of 1 ; if there is negative correlation, whenever one variable has a high (low) value, the other has a low (high) value. A correlation coefficient of 0 means that there is no linear relationship between the variables.

Correlation Test (Pearson): The statistical significance of $r$ is tested using a t-test. The hypotheses for this test are:

$$
\begin{aligned}
& \mathrm{H}_{0}: \text { rho }=0 \\
& \mathrm{H}_{\mathrm{a}}: \text { rho }<>0
\end{aligned}
$$

A low p-value for this test (less than 0.05 for example) means that there is evidence to reject the null hypothesis in favor of the alternative hypothesis, or that there is a statistically significant relationship between the two variables.

P-value: The probability of wrongly rejecting the null hypothesis if it is in fact true. Examples of null hypotheses used in this analyses:

$\mathrm{H}_{0}$ : The process is in a state of control

$\mathrm{H}_{0}$ : rho (correlation coefficient $)=0$

Simple Linear Regression: Simple linear regression aims to find a linear relationship between a response variable and a possible predictor variable by the method of least squares and production of a regression equation. A regression equation allows us to express the relationship between two variables algebraically. It indicates the nature of the relationship between two variables. In particular, it indicates the extent to which you can predict a variable by knowing another, or the extent to which variables are associated with one another.

Standard deviation: A way to measure how far the observations are from their mean. It is also referred to as a measure of spread.

State of Control: The extent of variation of the output of the process does not exceed that which is expected on the basis of the natural statistical variability of the process. None of the data points fall outside of the Upper or Lower Control Limits.

Statistically Significant: The probability (usually less than 5 percent or less than a p-value of 0.05 ) that a finding or result is caused by something other than just chance. 


\subsection{References}

Lawrence Livermore National Laboratory, ES\&H Manual Environment, Safety and Health Volume 1 Part 4: Feedback and Improvement, Document 4.1, "Principal Associate Directorate Environment, Safety and Health Self-Assessment Program," UCRL-AM-133867, Approval date of March 31, 2009, available online at https://esh-int.llnl.gov/man/4.1.pdf.

Lawrence Livermore National Laboratory, ES\&H Manual Environment, Safety and Health Volume 1 Part 4: Feedback and Improvement, Document 4.4, "Identifying, Reporting and Tracking Noncompliances with Nuclear Safety and Worker Safety and Health Requirements," UCRL-AM-133867-VOL-1-PT-4.42009, Approval date of July 20, 2009, available online at https://esh-int.1lnl.gov/man/4.4.pdf.

Lawrence Livermore National Laboratory, ES\&H Manual Environment, Safety and Health Volume V Part 51:Safety Analysis, Limits, and Authorization, Document 51.3, "LLNL Unreviewed Safety Question (USQ) Procedure," UCRL-AM-133867-VOL-5-PT-51.3-2008, Approval date of September 2, 2008, available online at https://esh-int.llnl.gov/man/4.4.pdf.

Lawrence Livermore National Laboratory, LLNL Approved Document for Contractor Assurance, PRO004200, "Issues and Corrective Action Management," LLNL-AM-412811, Effective Date of June 1, 2009, available online at https://portal.1lnl.gov/portal/page/portal/MYLLNL/ITEMS/DOCUMENTS/BOOKSHELF/PRO 0042 Iss ues_and_Corrective_Action_Management.pdf.

Lawrence Livermore National Laboratory, "Worker Safety and Health Program," Approval date by LLNL of April 15, 2008, Approval date by LSO of October 7, 2009.

Montgomery, D. (1997), Introduction to Statistical Quality Control (John Wiley \& Sons, Inc., New York, NY).

U.S. Department of Energy Office of Enforcement (June 2009), Enforcement Process Overview, available online at http://www.hss.energy.gov/enforce/Final_EPO_June_2009 v4.pdf. 